\title{
Henry's law constants of polyols
}

\author{
S. Compernolle and J.-F. Müller \\ Belgian Institute for Space-Aeronomy, 1180 Brussels, Belgium \\ Correspondence to: S. Compernolle (steven.compernolle@ aeronomie.be) \\ Received: 8 May 2014 - Published in Atmos. Chem. Phys. Discuss.: 23 May 2014 \\ Revised: 24 October 2014 - Accepted: 12 November 2014 - Published: 8 December 2014
}

\begin{abstract}
Henry's law constants (HLC) are derived for several polyols bearing between 2 and 6 hydroxyl groups, based on literature data for water activity, vapour pressure and/or solubility. While deriving HLC and depending on the case, also infinite dilution activity coefficients (IDACs), solid state vapour pressures or activity coefficient ratios are obtained as intermediate results. An error analysis on the intermediate quantities and the obtained HLC is included. For most compounds, these are the first values reported, while others compare favourably with literature data in most cases. Using these values and those from a previous work (Compernolle and Müller, 2014), an assessment is made on the partitioning of polyols, diacids and hydroxy acids to droplet and aqueous aerosol.
\end{abstract}

\section{Introduction}

Henry's law constant (HLC) describes the partitioning of a compound between the gas phase and a liquid, highly dilute solution. In the atmosphere, such dilute solutions, with water as the solvent, can be reached in cloud droplets. Aqueous aerosols are another example where liquid water is important, but in this case the solvent must be regarded as multicomponent, with significant inorganic and/or organic contributions. In a previous work (Compernolle and Müller, 2014) we determined additional HLC data for diacids and hydroxy polyacids, from water activities, solubilities and vapour pressures, employing thermodynamic relationships. We follow the same approach in this work, but with a focus on polyols: compounds with two or more hydroxyl groups, but no other functional group. Polyols such as 2-methyl tetrols were identified as important secondary organic aerosol (SOA) constituents (Claeys et al., 2004). HLC data on polyols are limited. Data are available e.g. in the often-cited compilation of Sander (1999). In this compilation however, most values are estimated by a group-contribution method, while only for three molecules are experimental values included, and some of the data were evaluated as unreliable.

In Sect. 2, we first briefly review the thermodynamic relationships employed to derive HLC $\left(k_{h}\right)$ and the associated enthalpy of dissolution of a gas phase species $\left(\Delta H_{\mathrm{g} \rightarrow \mathrm{aq}}^{\infty}\right)$. In Sect. 3 we derive intermediate results, namely infinite dilution activity coefficients (IDACs), solid state vapour pressures and activity coefficient ratios, which are necessary components in deriving HLC but not as such available in the literature for all compounds. Next (Sect. 4), we present $k_{h}$ and $\Delta H_{\mathrm{g} \rightarrow \mathrm{aq}}^{\infty}$ using the data from the previous section and other literature data. An error analysis is presented in Appendix A. In Sect. 5, we discuss the implications for partitioning to cloud droplets and aqueous ammonium sulfate aerosol, making use of the activity coefficient model AIOMFAC (Aerosol Inorganic-Organic Mixtures Functional groups Activity Coefficients) (Zuend et al., 2011). We extend this also to dicarboxylic acids and hydroxy polyacids, making use of a model presented at the site E-AIM (Extended AIM Aerosol Thermodynamics Model), available at http://www.aim.env.uea.ac.uk/aim/aim.php, (see e.g. Clegg and Seinfeld, 2006; Friese and Ebel, 2010) to calculate the acid dissociation.

Note that in this work, non-IUPAC names are used for polyols with three or more hydroxyl groups. Their structures are presented in Table 1. 


\section{Thermodynamic relationships between HLC and other quantities}

For HLC, several definitions exist. We will follow here the convention used by Sander (1999):

$k_{h} \equiv \lim _{c_{\mathrm{s}}, p_{\mathrm{s}} \rightarrow 0} \frac{c_{\mathrm{s}}}{p_{\mathrm{s}}}$

with $c_{\mathrm{S}}$ the solute molar concentration of the solution and $p_{\mathrm{s}}$ its partial pressure above it. Note that we assume ideal gas behaviour for the solute. With this convention, a larger $k_{h}$ means a higher partitioning of the solute to the solution. At some point, we will employ also another definition of HLC, following again the notation of Sander (1999),

$k_{h}^{p x} \equiv \lim _{x_{\mathrm{s}}, p_{\mathrm{s}} \rightarrow 0} \frac{x_{\mathrm{s}}}{p_{\mathrm{s}}}$

with $x_{\mathrm{S}}$ the solute mole fraction. The $p x$ superscript specifies that vapour pressure $p$ is used for the gas phase concentration, and mole fraction $x$ for the aqueous phase concentration.

The relation between both quantities is

$k_{h} / k_{h}^{p x}=c_{\text {sol }}$

with $c_{\text {sol }}$ the total molar concentration of the solution (or solvent, since we assume that the solute is infinitely diluted). In the case that the solvent is pure water, we write $c_{\mathrm{sol}}=c_{\mathrm{W}}$ (equal to $55.5 \mathrm{~mol} \mathrm{~L}^{-1}$ at $298.15 \mathrm{~K}$ ).

If the solute is a liquid at the temperature of interest and the solvent is water, $k_{h}$ can be obtained by

$k_{h}=\frac{c_{\mathrm{W}}}{\gamma^{\infty} p_{\mathrm{L}}^{0}}$

with $\gamma^{\infty}$ the infinite dilution activity coefficient (IDAC) of the solute (mole fraction based and with the symmetric convention $\gamma^{\infty}=1$ for pure liquid solute) and $p_{\mathrm{L}}^{0}$ its pure liquid state vapour pressure. The corresponding enthalpy of dissolution of an infinitesimal amount of gas phase species $\left(\Delta H_{\mathrm{g} \rightarrow \mathrm{aq}}^{\infty}\right)$ can be derived from the van 't Hoff equation (see e.g. Atkins and de Paula, 2006) and (neglecting the small temperature dependence of $c_{\mathrm{W}}$ ) related to the enthalpy of vaporization $\left(\Delta H_{\mathrm{vap}}\right)$ and the enthalpy of solution of the liquid solute at infinite dilution $\left(\Delta H_{\mathrm{L} \rightarrow \mathrm{aq}}^{\infty}\right.$ ) using Hess's law (Atkins and de Paula, 2006),

$$
\begin{aligned}
-R \frac{d \ln k_{h}}{d(1 / T)} & =\Delta H_{\mathrm{g} \rightarrow \mathrm{aq}}^{\infty} \\
& =\Delta H_{\mathrm{L} \rightarrow \mathrm{aq}}^{\infty}-\Delta H_{\mathrm{vap}}
\end{aligned}
$$

since the dissolution of a gas in a solvent can be considered as first a condensation of the gas to the pure liquid (corresponding to $-\Delta H_{\text {vap }}$ ) followed by a dissolution of this liquid in the solvent (corresponding to $\Delta H_{\mathrm{L} \rightarrow \mathrm{aq}}^{\infty}$ ). $\Delta H_{\text {vap }}$ and $\Delta H_{\mathrm{L} \rightarrow \mathrm{aq}}^{\infty}$ can themselves be derived from the van 't Hoff equation or, for Eq. (7), from the Clausius-Clapeyron equation (Atkins and de Paula, 2006):

$$
\begin{aligned}
\Delta H_{\mathrm{L} \rightarrow \mathrm{aq}}^{\infty} & =R \frac{d \ln \gamma^{\infty}}{d(1 / T)} \\
\Delta H_{\text {vap }} & =-R \frac{d \ln p_{\mathrm{L}}^{0}}{d(1 / T)} .
\end{aligned}
$$

If the solute is a solid at room temperature, as is generally the case for polyols with more than three hydroxyl groups, the following equation can be applied instead of Eq. (4) (see Compernolle and Müller, 2014, for the derivation):

$k_{h}=\frac{\gamma^{\text {sat }}}{\gamma^{\infty}} \frac{c_{\mathrm{w}} x^{\mathrm{sat}}}{p_{\mathrm{Cr}}^{0}}$

with $x^{\text {sat }}$ the solute mole fraction at the solubility limit and $\gamma^{\text {sat }}$ the corresponding activity coefficient. In the case that the solubility is small, $\gamma^{\infty} / \gamma^{\text {sat }} \approx 1$ and Eq. (8) reduces to

$k_{h} \approx c_{\mathrm{w}} \frac{x^{\mathrm{sat}}}{p_{\mathrm{Cr}}^{0}}$.

The corresponding enthalpy of dissolution of gas phase species, derived from the van 't Hoff equation, can be related to (again neglecting the temperature dependence of $c_{\mathrm{w}}$ ) the sublimation enthalpy $\left(\Delta H_{\text {sub }}\right)$ and the enthalpy of solution of the solid at infinite dilution $\left(\Delta H_{\mathrm{Cr} \rightarrow \mathrm{aq}}^{\infty}\right)$ using Hess's law (Atkins and de Paula, 2006),

$$
\begin{aligned}
\Delta H_{\mathrm{g} \rightarrow \mathrm{aq}}^{\infty} & =-R \frac{d \ln k_{h}}{d(1 / T)} \\
& =\Delta H_{\mathrm{Cr} \rightarrow \mathrm{aq}}^{\infty}-\Delta H_{\text {sub }}
\end{aligned}
$$

with

$$
\begin{aligned}
\Delta H_{\mathrm{sub}} & =-R \frac{d \ln p_{\mathrm{Cr}}^{0}}{d(1 / T)} \\
\Delta H_{\mathrm{Cr} \rightarrow \mathrm{aq}}^{\infty} & =-R \frac{d \ln \frac{\gamma^{\mathrm{sat}} x^{\mathrm{sat}}}{\gamma^{\infty}}}{d(1 / T)} \\
& =\Delta H_{\text {fus }}+\Delta H_{\mathrm{L} \rightarrow \mathrm{aq}}^{\infty} .
\end{aligned}
$$

Equation (11) is the Clausius-Clapeyron equation for sublimation (Atkins and de Paula, 2006). Equation (12) can be derived by combining Eqs. (6) and (8) and the van 't Hoff relation for the activity of the solid $a_{\mathrm{s}}^{\mathrm{Cr}}$ (see e.g. Nordström and Rasmuson, 2008):

$$
\frac{d \ln \gamma_{\mathrm{s}}^{\mathrm{sat}} x_{\mathrm{s}}^{\mathrm{sat}}}{d(1 / T)}=\frac{d \ln a_{\mathrm{s}}^{\mathrm{Cr}}}{d(1 / T)}=-\frac{\Delta H_{\mathrm{fus}}}{R} .
$$

The data required for Eqs. (4), (5), (8) and (10) is not always available in the literature. In Sect. 3, data for IDACs, solid state pressures and activity coefficient ratios are derived. 
Table 1. Molecular structures of polyols with three or more hydroxyl groups, discussed in this work using non-IUPAC names.

\begin{tabular}{lll|ll}
\hline name & \# $\mathrm{OH}$ & structure & name & \# $\mathrm{OH}$
\end{tabular}

\section{Intermediate results}

\subsection{Infinite dilution activity coefficients}

In the case that the compound is a liquid at room temperature, Eq. (4) applies and the IDAC is required. Estimation methods to calculate activity coefficients exist (e.g. Fredenslund et al., 1975; Peng et al., 2001; Marcolli and Peter, 2005; Compernolle et al., 2009; Zuend et al., 2011) but experimental data are preferred. Suleiman and Eckert (1994) provide IDAC data for diols, but only for compounds with up to four carbon atoms. For many other polyols, the IDAC of the solute is not reported, but instead data are available on the water activity $a_{\mathrm{w}}$ as a function of mixture composition. In that case, $\gamma_{\mathrm{s}}^{\infty}$ can be obtained by the Gibbs-Duhem relation (here stated in its integral form) (Prausnitz et al., 1999; Mansoori, 1980),

$\ln \gamma_{\mathrm{s}}^{\infty}=\int_{0}^{1} \frac{\ln \gamma_{\mathrm{w}}\left(x_{\mathrm{w}}\right)}{\left(1-x_{\mathrm{w}}\right)^{2}} \mathrm{~d} x_{\mathrm{w}}$

with $\gamma_{\mathrm{w}}=a_{\mathrm{w}} / x_{\mathrm{w}}$ the activity coefficient of water and $x_{\mathrm{w}}$ the water mole fraction. Note that we added the subscript "s" to $\gamma^{\infty}$ to distinguish clearly the activity coefficient of the solute and the activity coefficient of water.

If sufficiently precise, fine-grained $a_{\mathrm{w}}$ data over the whole composition range would be available, and numeric integration of the integral in Eq. (14) would be the most straightforward. If this is not the case, an alternative is to fit the $\ln \gamma_{\mathrm{w}}$ data with an activity coefficient expression $f$, e.g. Margules, Van Laar, Wilson or UNIQUAC (Prausnitz et al., 1999; Carlson and Colburn, 1942) - see Appendix A2 for the expressions.
Marcolli and Peter (2005) provide $a_{\mathrm{w}}$ data for 14 diols and two triols over a broad composition range ( $x_{\mathrm{w}}$ typically between 0.1 and 0.95 .), but the data are rather coarse grained. This is especially critical in the dilute region; from Eq. (14) it can be concluded that a small change in $\ln \gamma_{\mathrm{w}}$ leads to a comparatively large change in $\ln \gamma_{\mathrm{s}}$. Therefore, where possible, we included also more fine-grained data in the dilute region (Borghesani et al., 1989; Romero and Páez, 2006, $x_{\mathrm{w}}$ typically between 0.93 and 0.996 ). In Table 2 the resulting $\gamma_{\mathrm{s}}^{\infty}$ are presented. For eight diols we present also the $\gamma_{\mathrm{s}}^{\infty}$ estimation without taking the available dilute region data into account, i.e. based on the Marcolli and Peter (2005) data only. This can then be compared with the $\gamma_{\mathrm{s}}^{\infty}$ based on all data. In most cases, the difference in the resulting IDAC is rather small (see Appendix A2). This indicates that even in those cases where only the coarse-grained data of Marcolli and Peter (2005) are available, the derived $\gamma_{\mathrm{s}}^{\infty}$ are still quite reliable.

Often, we were able to fit an activity expression to all $\ln \gamma_{\mathrm{w}}$ data. In other cases, where the broad-ranged but coarsegrained data of Marcolli and Peter (2005) was combined with the more fine-grained data in the dilute region, we had to split the integral in Eq. (14) into two parts. More details on the procedure to derive $\gamma_{\mathrm{s}}^{\infty}$ are provided in Appendix A2. Also included in Appendix A2 is an uncertainty analysis in the derived $\gamma_{\mathrm{s}}^{\infty}$ values by applying systematic and random shifts to the $a_{\mathrm{w}}$ data, by testing alternative activity expressions and by comparing $\gamma_{\mathrm{s}}^{\infty}$ derived with and without dilute region data.

The $\gamma_{\mathrm{s}}^{\infty}$ for pentane and hexane diols, derived from surface tension data, are reported by Romero et al. (2007) and Páez et al. (2011). These are considerably higher than the data presented in Table 2. However, as explained by Brocos et al. (2007), very accurate surface tension data are a prerequisite to derive $\gamma_{\mathrm{s}}^{\infty}$; the $\gamma_{\mathrm{s}}^{\infty}$ of diols, derived from surface 
Table 2. Infinite dilution activity coefficients derived in this work, the sources of water activity they are based on, and comparison with the literature.

\begin{tabular}{lccc}
\hline molecule & $\gamma_{\mathrm{s}}^{\infty}$ & $a_{\mathrm{w}}$ source & $\gamma_{\mathrm{s}}^{\infty}$ (lit.) $^{\mathrm{f}}$ \\
\hline 1,2-ethane diol & $0.75,0.69^{\mathrm{g}}$ & $\mathrm{a}, \mathrm{b}$ & 0.8 \\
1,2-propane diol & $1.25,1.08^{\mathrm{g}}$ & $\mathrm{a}, \mathrm{b}$ & 1.0 \\
1,3-propane diol & $1.23,1.25^{\mathrm{g}}$ & $\mathrm{a}, \mathrm{b}$ & 1.2 \\
1,2-butane diol & $3.00,3.74^{\mathrm{g}}$ & $\mathrm{a}, \mathrm{b}, \mathrm{c}$ & 2.0 \\
1,3-butane diol & $2.14,1.97^{\mathrm{g}}$ & $\mathrm{a}, \mathrm{b}, \mathrm{c}$ & 2.2 \\
1,4-butane diol & $2.27,2.12^{\mathrm{g}}$ & $\mathrm{a}, \mathrm{b}, \mathrm{c}$ & 2.8 \\
2,3-butane diol & $2.10,1.77^{\mathrm{g}}$ & $\mathrm{a}, \mathrm{b}, \mathrm{c}$ & 1.6 \\
1,5-pentane diol & $5.99,5.26^{\mathrm{g}}$ & $\mathrm{a}, \mathrm{b}$ & \\
1,2-pentane diol & 11.9 & $\mathrm{a}$ & \\
1,4-pentane diol & 3.8 & $\mathrm{a}$ & \\
2,4-pentane diol & 2.8 & $\mathrm{a}$ & \\
1,2-hexane diol & 26.3 & $\mathrm{a}$ & \\
2,5-hexane diol & 5.7 & $\mathrm{a}$ & \\
1,7-heptane diol & 27.9 & $\mathrm{a}$ & \\
glycerol & 0.52 & $\mathrm{a}, \mathrm{d}, \mathrm{e}$ & \\
1,2,4-butane triol & 0.45 & $\mathrm{a}, \mathrm{d}$ &
\end{tabular}

${ }^{\mathrm{a}}$ Marcolli and Peter (2005). ${ }^{\mathrm{b}}$ Borghesani et al. (1989). ${ }^{\mathrm{c}}$ Romero and Páez (2006). ${ }^{\mathrm{d}}$ Ninni et al. (2000). ${ }^{\mathrm{e}}$ Scatchard et al. (1938). ${ }^{\mathrm{f}}$ Suleiman and Eckert (1994). $\mathrm{g}$ The second value is obtained by applying Eq. (14) to the data of Marcolli and Peter (2005) only.

tension data, are all overestimated compared to the literature data in their analysis. Moreover, it is not clear to us whether the applied approximation (the Volmer surface equation of state, see Gracia-Fadrique et al., 2002) is valid in this case.

\subsection{Solid state vapour pressures}

The liquid state vapour pressure of organic compounds can be estimated (e.g. Pankow and Asher, 2008; Nannoolal et al., 2008; Compernolle et al., 2011), but for polyfunctional compounds the result is often not accurate. Solid state vapour pressure is even more difficult to estimate, as this depends on the molecular arrangement in the crystal structure which is compound specific. Therefore, experimental data are preferred. Solid state and/or liquid state vapour pressure data for polyols with four or more hydroxyl groups is available (Barone et al., 1990; Bradley and Cotson, 1953; Nitta et al., 1950, 1951), but obtained at temperatures considerably above room temperature. The solid state vapour pressure at $T_{\text {ref }}=298.15 \mathrm{~K}$ is given by

$\ln p_{\mathrm{Cr}}^{0}\left(T_{\text {ref }}\right)=1 / R\left(\Delta S_{\text {sub }}\left(T_{\text {ref }}\right)-\frac{1}{T_{\text {ref }}} \Delta H_{\text {sub }}\left(T_{\text {ref }}\right)\right)$.

If at the temperature of measurement $T_{\text {meas }}$, the compound is a solid, the following temperature correction is applied
(Kirchhoff's law, see e.g. Atkins and de Paula, 2006):

$$
\begin{gathered}
\Delta S_{\text {sub }}\left(T_{\text {ref }}\right)=\Delta S_{\text {sub }}\left(T_{\text {meas }}\right)+\int_{T_{\text {meas }}}^{T_{\text {ref }}} \frac{C_{p, \mathrm{~g}}-C_{p, \mathrm{Cr}}}{T} \mathrm{~d} T \\
\Delta H_{\text {sub }}\left(T_{\text {ref }}\right)=\Delta H_{\text {sub }}\left(T_{\text {meas }}\right)+\int_{T_{\text {meas }}}^{T_{\text {ref }}}\left(C_{p, \mathrm{~g}}-C_{p, \mathrm{Cr}}\right) \mathrm{d} T
\end{gathered}
$$

with $\Delta H_{\text {sub }}$ and $\Delta S_{\text {sub }}$ weak functions of temperature. If at $T_{\text {meas }}$ the compound is a liquid, the fusion point must be taken into account, and the temperature correction is

$$
\begin{aligned}
& \Delta S_{\text {sub }}\left(T_{\text {ref }}\right)=\Delta S_{\text {vap }}\left(T_{\text {meas }}\right)+\int_{T_{\text {meas }}}^{T_{\text {fus }}} \frac{C_{p, \mathrm{~g}}-C_{p, \mathrm{~L}}}{T} \mathrm{~d} T+ \\
& \Delta S_{\text {fus }}\left(T_{\text {fus }}\right)+\int_{T_{\text {fus }}}^{T_{\text {ref }}} \frac{C_{p, \mathrm{~g}}-C_{p, \mathrm{Cr}}}{T} \mathrm{~d} T \Delta H_{\text {sub }}\left(T_{\text {ref }}\right)= \\
& \Delta H_{\text {vap }}\left(T_{\text {meas }}\right)+\int_{T_{\text {meas }}}^{T_{\text {fus }}}\left(C_{p, \mathrm{~g}}-C_{p, \mathrm{~L}}\right) \mathrm{d} T+ \\
& \Delta H_{\text {fus }}\left(T_{\text {fus }}\right)+\int_{T_{\text {fus }}}^{T_{\text {ref }}}\left(C_{p, \mathrm{~g}}-C_{p, \mathrm{Cr}}\right) \mathrm{d} T
\end{aligned}
$$

with $C_{p, \mathrm{~g}}, C_{p, \mathrm{~L}}, C_{p, \mathrm{Cr}}$ the constant pressure heat capacities for respectively gas, liquid and crystalline phase, $T_{\text {fus }}$ the melting temperature, $\Delta S_{\text {fus }}, \Delta H_{\text {fus }}$ the entropy and enthalpy of fusion, and $\Delta S_{\text {vap }}, \Delta H_{\text {vap }}$ the entropy and enthalpy of vaporization. In most cases, the high-temperature $p^{0}$ data are not measured at one temperature but in a temperature interval. $T_{\text {meas }}$ then corresponds to the centre of this interval.

Fusion data were taken from Barone et al. (1990), Tong et al. (2007, 2008, 2010a, 2009) and Badea et al. (2014). Experimental heat capacity data for solid and liquid were taken from Tong et al. (2007, 2008, 2009, 2010a, b), Zhang and Yang (1989) and Della Gatta et al. (1999), while for the gas it was calculated by the method of Benson (1976), available from the NIST Chemistry WebBook (Stein and Brown). In Table 3 the derived solid state vapour pressures and sublimation enthalpies at room temperature are presented.

Fusion data of Tong et al. (2007, 2008, 2010a, 2009) on one hand and of Barone et al. (1990) on the other hand could be compared for erythritol, xylitol, adonitol, sorbitol and mannitol. There is generally a good agreement between both data sets: $T_{\text {fus }}$ was always within $6 \mathrm{~K}$ and $\Delta H_{\text {fus }}$ within $4 \%$, with the exception of xylitol where the deviation is $11 \%$. Interchanging both data sets had an impact of a factor 1.3 on $p_{\mathrm{Cr}}^{0}$ at room temperature at most. Where available, the more recent data set of Tong et al. was preferred over that of Barone et al. (1990). 
Table 3. Solid state pressure and enthalpy of sublimation of polyols, obtained from Eqs. (15), (16) and/or (17), at $T_{\text {ref }}=298.15 \mathrm{~K}$, and reference to the data used to obtain them. $C_{p, \mathrm{~g}}$ is estimated by the method of Benson (1976).

\begin{tabular}{|c|c|c|c|c|c|c|}
\hline \multirow[t]{2}{*}{ Molecule } & \multirow{2}{*}{$\frac{p_{\mathrm{Cr}}^{0}\left(T_{\mathrm{ref}}\right)}{\mathrm{Pa}}$} & \multirow{2}{*}{$\frac{\Delta H_{\mathrm{sub}}\left(T_{\mathrm{ref}}\right)}{\mathrm{kJ} \mathrm{mol}^{-1}}$} & \multicolumn{4}{|c|}{ Data source for Eqs. (15), (16) and/or (17) } \\
\hline & & & $\begin{array}{c}p_{\mathrm{L}}^{0}, \Delta H_{\mathrm{vap}}(\mathrm{L})^{\mathrm{a}} \\
\text { or } p_{\mathrm{Cr}}^{0}, \Delta H_{\text {sub }}(\mathrm{Cr})\end{array}$ & $\frac{T \text { interval }}{\mathrm{K}}$ & $\begin{array}{c}T_{\text {fus }} \\
\Delta H_{\text {fus }}\end{array}$ & $\begin{array}{c}C_{p, \mathrm{~L}}(\mathrm{~L})^{\mathrm{a}} \\
\text { or } C_{p, \mathrm{Cr}}(\mathrm{Cr})\end{array}$ \\
\hline \multirow{6}{*}{$\begin{array}{l}\text { nonane- } \\
\text { diol } \\
\text { decane- } \\
\text { diol } \\
\text { erythritol }\end{array}$} & $1.4 \times 10^{-3}$ & 148 & $\mathrm{~L}^{\mathrm{b}}$ & 323 & g & $\mathrm{Cr}^{\mathrm{k}}, \mathrm{L}^{\mathrm{i}}$ \\
\hline & $2.4 \times 10^{-3}$ & 148 & $\mathrm{~L}^{\mathrm{c}}$ & $347-373$ & $\mathrm{~g}$ & $\mathrm{Cr}^{\mathrm{k}}, \mathrm{L}^{\mathrm{o}}$ \\
\hline & $1.4 \times 10^{-4}$ & 151 & $\mathrm{Cr}^{\mathrm{b}}$ & 342 & & $\mathrm{Cr}^{\mathrm{k}}$ \\
\hline & $1.7 \times 10^{-4}$ & 161 & $\mathrm{~L}^{\mathrm{c}}$ & $351-377$ & g & $\mathrm{Cr}^{\mathrm{k}}, \mathrm{L}^{\mathrm{o}}$ \\
\hline & $4.7 \times 10^{-7}$ & 155 & $\mathrm{~L}^{\mathrm{d}}$ & $397-428$ & $\mathrm{~h}$ & $\mathrm{~L}, \mathrm{Cr}^{\mathrm{h}}$ \\
\hline & $3.6 \times 10^{-6}$ & 136 & $\mathrm{Cr}^{\mathrm{e}}$ & $379-392$ & & $\mathrm{Cr}^{\mathrm{h}}$ \\
\hline \multirow{3}{*}{$\begin{array}{l}\text { penta- } \\
\text { erythritol }\end{array}$} & $7.2 \times 10^{-9}$ & 166 & $\mathrm{Cr}^{\mathrm{d}}$ & $416-456$ & & $\mathrm{Cr}^{\mathrm{j}}$ \\
\hline & $3.5 \times 10^{-7}$ & 135 & $\mathrm{Cr}^{\mathrm{e}}$ & $397-410$ & & $\mathrm{Cr}^{\mathrm{j}}$ \\
\hline & $9.3 \times 10^{-8}$ & 147 & $\mathrm{Cr}^{\mathrm{f}}$ & $380-408$ & & $\mathrm{Cr}^{\mathrm{j}}$ \\
\hline \multirow{6}{*}{$\begin{array}{l}\text { xylitol } \\
\text { adonitol } \\
\text { arabinitol } \\
\text { sorbitol } \\
\text { mannitol } \\
\text { dulcitol }\end{array}$} & $7.5 \times 10^{-8}$ & 162 & $\mathrm{~L}^{\mathrm{d}}$ & $406-460$ & $\mathrm{~h}$ & $\mathrm{~L}, \mathrm{Cr}^{\mathrm{h}}$ \\
\hline & $2.7 \times 10^{-8}$ & 166 & $\mathrm{~L}^{\mathrm{d}}$ & $418-465$ & $\mathrm{~h}$ & $\mathrm{~L}, \mathrm{Cr}^{\mathrm{h}}$ \\
\hline & $2.1 \times 10^{-8}$ & 166 & $L^{d}$ & $414-466$ & d & $\mathrm{L}, \mathrm{Cr}^{1}$ \\
\hline & $3.6 \times 10^{-11}$ & 198 & $\mathrm{~L}^{\mathrm{d}}$ & $452-502$ & $\mathrm{~h}$ & $\mathrm{~L}, \mathrm{Cr}^{\mathrm{h}}$ \\
\hline & $6.7 \times 10^{-13}$ & 206 & $L^{d}$ & $458-501$ & $\mathrm{~h}$ & $\mathrm{Cr}^{\mathrm{h}}, \mathrm{L}^{\mathrm{m}}$ \\
\hline & $1.9 \times 10^{-13}$ & 210 & $\mathrm{~L}^{\mathrm{d}}$ & $464-500$ & d & $\mathrm{Cr}^{\mathrm{n}}, \mathrm{L}^{\mathrm{m}}$ \\
\hline $\begin{array}{l}\text { a "L" (liquid) ar } \\
\text { (1990a), c Piace } \\
\text { (2014), h Tong c } \\
\text { No } C_{p, \text {, Cr }, C_{p, \mathrm{~L}} \mathrm{~L}} \\
\text { dulcitol in the li } \\
\text { range. Low-tem } \\
\text { was taken instea } \\
\text { (1993). }\end{array}$ & $\begin{array}{l}\text { " (crystalline) } \\
\text { al. }(1993,199 \\
2007,2008,2 \\
\text { were found for } \\
\text { re; the } C_{p, \mathrm{~L}} \mathrm{~d} \\
\text { re }(\leq 292.8 \mathrm{~K})\end{array}$ & $\begin{array}{l}\text { used as shortha } \\
\text { d Barone et al. } \\
\text { 2010b, a), }{ }^{\mathrm{i}} \text { Go } \\
\text { abinitol. The dat } \\
\text { for sorbitol wer } \\
\text { ta (Parks and Hu }\end{array}$ & $\begin{array}{l}\text { describe the phase state } \\
\text { )), }{ }^{\mathrm{e}} \text { Nitta et al. }(1950,195 \\
\text { ki and Tkaczyk (2008), }{ }^{\mathrm{j}} \mathrm{Z} \\
\text { adonitol were taken inste } \\
\text { en instead. }{ }^{\mathrm{n}} \text { No } C_{p, \text { Cr }} \text { dat } \\
\text { an, 1926) are comparable } \\
\text { nd in the literature. It was }\end{array}$ & $\begin{array}{l}\text { the non-gaseo } \\
),{ }^{\mathrm{f}} \text { Bradley an } \\
\text { ang and Yang } \\
\mathrm{t}^{\mathrm{m}} \text { No } C_{p, \mathrm{~L}} \mathrm{~d} \\
\text { were found for } \\
\text { those of mann }\end{array}$ & $\begin{array}{l}\text { hase. }{ }^{b} \\
\text { tson (1 } \\
9),{ }^{k} D \\
\text { were fo }\end{array}$ & $\begin{array}{l}\text { auth and Sabbah } \\
\text { g }{ }^{\mathrm{g}} \text { Badea et al. } \\
\text { Gatta et al. (1999). } \\
\text { for mannitol and } \\
\text { desired temperature } \\
C_{p, \mathrm{Cr}} \text { of mannitol } \\
\text { malski and Hearing }\end{array}$ \\
\hline
\end{tabular}

$C_{p, \mathrm{~L}}$ and $C_{p, \mathrm{Cr}}$ were not always available. In that case, the data of a stereo-isomer were taken instead. In Appendix A5.2, it is shown that liquid phase heat capacities of polyol stereo-isomers are very close. This is in agreement with the similar $\Delta S_{\text {vap }}$ and $\Delta H_{\text {vap }}$ of stereo-isomers reported by Barone et al. (1990) and indicates similar thermodynamic properties of the liquid phase. Regarding $C_{p, \mathrm{Cr}}$, differences between stereo-isomers are larger (see Appendix A5.2) but still the approximation of using a stereo-isomer seems reasonable.

Neglecting the integrals involving the heat capacity differences in Eqs. (16) and (17) can lead to serious error: while for the tetrols the change is only minor, there is a factor of 5 to 7 increase in $p_{\mathrm{Cr}}^{0}(298.15 \mathrm{~K})$ for the pentols and most hexols, and a factor 40 increase for sorbitol. Estimating $C_{p, \mathrm{~g}}$ with the method of Joback and Reid (1987) instead of the method of Benson (1976) led to changes in $p_{\mathrm{Cr}}^{0}(298.15 \mathrm{~K})$ smaller than a factor of 2. Note that these two methods do not take the intramolecular hydrogen bonding into account. The group contribution $C_{p, \mathrm{~g}}$ estimation method of Paraskevas et al. (2013) and Sabbe et al. (2008), based on quantum chemical data, does include corrections for intramolecular hydrogen bonds. However, it is not clear how to apply these correction terms for species with three or more hydroxyl groups. Using one HOCCO term (NNI5 in the terminology of Paraskevas et al.
(2013)) per hydroxyl group for the linear polyols, one obtains a factor of 2 to 3 higher $p_{\mathrm{Cr}}^{0}(298.15 \mathrm{~K})$ for the pentols and hexols, compared to the case when this term is neglected.

In most cases the high-temperature $p_{\mathrm{L}}^{0}$ or $p_{\mathrm{Cr}}^{0}$ data are obtained from a single reference (Barone et al., 1990); only for erythritol and pentaerythritol is a comparison possible between different data sources. The high-temperature $p_{\mathrm{L}}^{0}$ or $p_{\mathrm{Cr}}^{0}$ data of erythritol and pentaerythritol are roughly comparable among the different data sources (Barone et al., 1990; Bradley and Cotson, 1953; Nitta et al., 1951, 1950); if the $p^{0}$ parameterizations presented in these works are evaluated at mid-points between their respective $T_{\text {meas }}$, differences ranging from $4 \%$ up to $40 \%$ are obtained. However, due to differences in $\Delta H_{\text {vap }}$ or $\Delta H_{\text {sub }}$, the extrapolated $p_{\mathrm{Cr}}^{0}(298.15 \mathrm{~K})$ is a factor of 7 to 50 higher if the older data of Nitta et al. (1950, 1951); Bradley and Cotson (1953) are used, compared to when the more recent data of Barone et al. (1990) are used. In the older studies the enthalpy was determined using far fewer data points (6-11, compared to 25-30 for the data of Barone et al., 1990), and specifically for the data of Nitta et al. (1950, 1951), over a quite narrow temperature interval ( $\sim 12 \mathrm{~K}$, compared to $30-40 \mathrm{~K}$ for the other studies). Therefore, we consider the $p_{\mathrm{Cr}}^{0}$ derived from the high-temperature data of Barone et al. (1990) as more reliable. 
Table 4. Mole fraction solubilities $x_{\mathrm{s}}^{\text {sat }}$ and activity coefficient ratios $\gamma_{\mathrm{s}}^{\infty} / \gamma_{\mathrm{s}}^{\text {sat }}$ derived from $a_{\mathrm{w}}$ data. Estimations of $\gamma_{\mathrm{s}}^{\infty} / \gamma_{\mathrm{s}}^{\text {sat }}$ by UNIFACMP are also given.

\begin{tabular}{lcccc}
\hline Molecule & $x_{\mathrm{s}}^{\mathrm{sat}}$ & $\gamma_{\mathrm{s}}^{\infty} / \gamma_{\mathrm{s}}^{\mathrm{sat}}$ & $a_{\mathrm{w}}$ data source & $\gamma_{\mathrm{s}}^{\infty} / \gamma_{\mathrm{s}}^{\mathrm{sat}} \mathrm{MP}$ \\
\hline nonane diol & $1 \times 10^{-3 \mathrm{a}}$ & $1.0^{\mathrm{p}}$ & - & 1.06 \\
decane diol & $7.6 \times 10^{-5 \mathrm{a}}$ & $1.0^{\mathrm{p}}$ & - & 1.01 \\
erythritol & $0.074^{\mathrm{b}}$ & 0.84 & $\mathrm{~h}, \mathrm{k}, \mathrm{i}$ & 0.75 \\
pentaerythritol & $0.00946^{\mathrm{c}}$ & $1.0^{\mathrm{q}}$ & - & 0.97 \\
xylitol & $0.18^{\mathrm{e}}$ & 0.56 & $\mathrm{~h}, \mathrm{j}$ & 0.32 \\
adonitol & $0.15^{\mathrm{d}}$ & $0.66^{1}$ & 1 & 0.37 \\
arabinitol & $0.20^{\mathrm{d}}$ & $0.60^{\mathrm{l}}$ & 1 & 0.30 \\
sorbitol & $0.196^{\mathrm{g}}$ & $0.45^{\mathrm{o}}$ & $\mathrm{h}, \mathrm{j}, \mathrm{m}$ & 0.18 \\
mannitol & $0.0209^{\mathrm{f}}$ & $0.96^{\mathrm{n}}$ & $\mathrm{h}, \mathrm{m}$ & 0.80 \\
dulcitol & $0.0031^{\mathrm{d}}$ & $1.0^{\mathrm{p}}$ & - & 0.97 \\
\hline
\end{tabular}

Solubilities: ${ }^{a}$ Merck Millipore (http://www.merckmillipore.com/), at $20^{\circ} \mathrm{C},{ }^{\mathrm{b}}$ Hao et al. (2005),

${ }^{\mathrm{c}}$ Cheon et al. (2005), ${ }^{\mathrm{d}}$ Cohen et al. (1993), ${ }^{\mathrm{e}}$ Wang et al. (2013), ${ }^{\mathrm{f}}$ Seidell (1941), ${ }^{\mathrm{g}}$ Mullin (2001).

Water activities: ${ }^{\mathrm{h}}$ Ninni et al. (2000), ${ }^{\mathrm{i}}$ Bonner and Breazeale (1965), ${ }^{\mathrm{j}}$ Comesaña et al. (2001),

${ }^{\mathrm{k}}$ Romero and Páez (2006), ${ }^{1}$ Chirife et al. (1984) (one-parameter fittings), ${ }^{\mathrm{m}}$ Robinson and Stokes (1961); Bower and Robinson (1963).

${ }^{\mathrm{n}}$ For mannitol, only the $a_{\mathrm{W}}$ data of Robinson and Stokes (1961) were used, as the data of Ninni et al.

(2000) led to $\gamma_{\mathrm{w}}>1$, which is probably wrong.

${ }^{\circ}$ Due to the extrapolation involved (no $a_{\mathrm{w}}$ data at $x_{\mathrm{sat}}$ ), this value is more uncertain.

$\mathrm{p}$ No $a_{\mathrm{W}}$ data were found. $\gamma_{\mathrm{s}}^{\infty} / \gamma_{\mathrm{s}}^{\mathrm{sat}}=1$ was assumed because of the low solubility, i.e. Eq. (9) is considered valid.

Uncertainties in the derivation of $p_{\mathrm{Cr}}^{0}\left(T_{\text {ref }}\right)$ are analysed in Appendix A5. The largest uncertainties are encountered for the polyols with four or more hydroxyl groups; due to the large difference between $T_{\text {meas }}$ and $T_{\text {ref }}$, relatively small changes in $\Delta H_{\text {vap }}$ or $\Delta H_{\text {sub }}$ lead to large changes in $p_{\mathrm{Cr}}^{0}\left(T_{\text {ref }}\right)$. Uncertainty in heat capacity becomes important for the hexols. Uncertainty in fusion data is relatively unimportant.

\subsection{Activity coefficient ratios}

The ratio $\gamma_{\mathrm{s}}^{\infty} / \gamma_{\mathrm{s}}^{\text {sat }}$ can be obtained from water activity data in the subsaturation range (Compernolle and Müller, 2014):

$$
\begin{aligned}
\ln \frac{\gamma_{\mathrm{s}}^{\infty}}{\gamma_{\mathrm{s}}^{\mathrm{sat}}} & =\frac{1-x_{\mathrm{s}}^{\mathrm{sat}}}{x_{\mathrm{s}}^{\mathrm{sat}}} \ln \gamma_{\mathrm{w}}\left(\widetilde{x}_{\mathrm{w}}\right)+\int_{\widetilde{x}_{\mathrm{w}}}^{1} \frac{\ln \gamma_{\mathrm{w}}\left(x_{\mathrm{w}}\right)}{\left(1-x_{\mathrm{w}}\right)^{2}} \mathrm{~d} x_{\mathrm{w}} \\
\tilde{x}_{\mathrm{w}} & =1-x_{\mathrm{s}}^{\mathrm{sat}} .
\end{aligned}
$$

The polyols with more than three hydroxyl groups considered here are solid at room temperature. Their water activity is only measured up to the solubility limit, if measured at all. Similarly to our previous work (Compernolle and Müller, 2014), activity coefficient expressions - Margules, Van Laar, Wilson (see e.g. Prausnitz et al., 1999; Carlson and Colburn, 1942) - were fitted to $a_{\mathrm{w}}$ data in the subsaturation range, and the fitting parameters were used to obtain the solute activity coefficient ratio $\gamma_{\mathrm{s}}^{\infty} / \gamma_{\mathrm{s}}^{\text {sat }}$.

The precise procedure is described in Appendix A of Compernolle and Müller (2014), and the resulting parameters are shown in Fig. 1.
This was done for erythritol, xylitol, sorbitol and mannitol (Fig. 1). The UNIFAC (UNIQUAC Functional-Group Activity Coefficient) method of Marcolli and Peter (2005) (UNIFAC-MP, identical to AIOMFAC for polyol-water systems) underestimates $\gamma_{\mathrm{w}}$ of these polyol/water mixtures.

For adonitol and arabinitol, we calculated $\gamma_{\mathrm{s}}^{\infty} / \gamma_{\mathrm{s}}^{\text {sat }}$ from the one-parameter Margules fittings of Chirife et al. (1984) (see Appendix A4). The results are presented in Table 4. For nonane diol, decane diol, pentaerythritol and dulcitol, no $a_{\mathrm{w}}$ data were found, but reasonable assumptions for $\gamma_{\mathrm{s}}^{\infty} / \gamma_{\mathrm{s}}^{\text {sat }}$ could be made (see Table 4). As expected, the polyols with a lower solubility (erythritol, mannitol) have $\gamma_{\mathrm{s}}^{\infty} / \gamma_{\mathrm{s}}^{\text {sat }}$ close to unity. We included estimations of the activity coefficient ratio by UNIFAC-MP. This method gave lower $\gamma_{\mathrm{s}}^{\infty} / \gamma_{\mathrm{s}}^{\text {sat }}$ as compared to our results.

\section{Henry's law constants and enthalpies of gas dissolution}

Using Eqs. $(4,5,8,10)$, the data provided in the previous tables, as well as literature data, the Henry's law constants and gas dissolution enthalpies can be derived. The values are given in Table 5.

The expected order hexols $>$ pentols $>$ tetrols $>$ triol $>$ diols in $k_{h}$ is generally followed. Diols have $k_{h}$ between $10^{5}$ and $10^{7} \mathrm{Matm}^{-1}$. The diols with longer hydrophobic chains have considerably lower $k_{h}$ than their $\alpha, \omega$ counterparts (e.g. an order of magnitude difference between 1,2and 1,5-pentane diol). For the linear polyols, $k_{h}$ and $\Delta H_{\mathrm{g} \rightarrow \mathrm{aq}}^{\infty}$ are roughly comparable among the different stereo-isomers. 

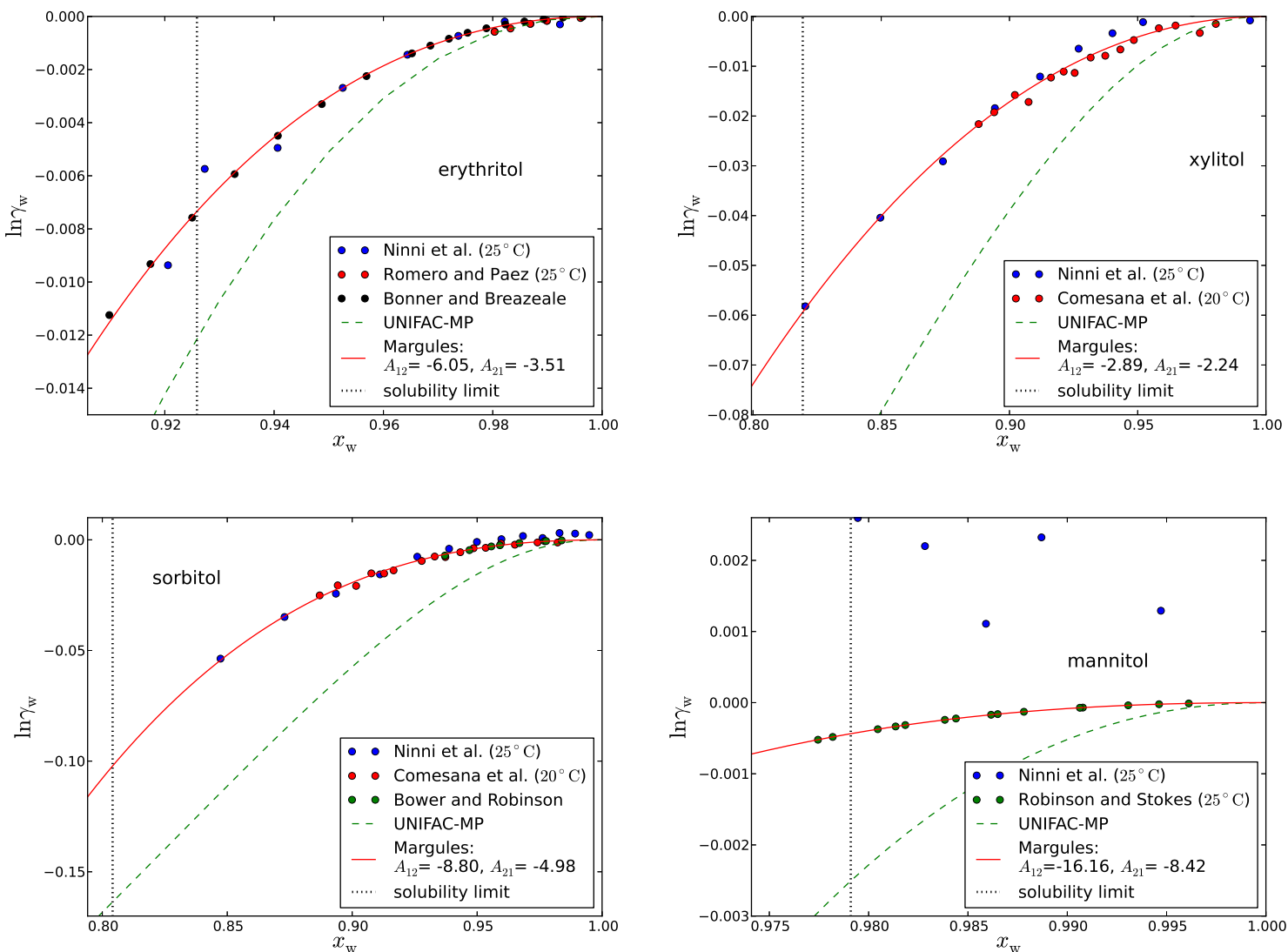

Figure 1. The $\ln \gamma_{\mathrm{w}}$ data for erythritol, xylitol, mannitol and sorbitol, compared with the fitting using the Margules formula, and UNIFACMP results. Note that the data of Comesaña et al. (2001) are at $20^{\circ} \mathrm{C}$ rather than $25^{\circ} \mathrm{C}$, but from their data at $35^{\circ} \mathrm{C}$, it can be deduced that the temperature dependence of $\ln \gamma_{\mathrm{w}}$ is small.

Clearly, the large differences in $x^{\text {sat }}$ and $p_{\mathrm{Cr}}^{0}$ of the hexols are mainly due to their different crystal structure, which does not affect $k_{h}$. Although pentaerythritol has the same number of hydroxyl groups as erythritol, its $k_{h}$ is seven times larger. Probably the tetragonal arrangement of the hydroxyl groups of pentaerythritol facilitates bonding with the water molecules.

\section{Impact on gas-particle partitioning}

Similarly as for the diacids and hydroxy polyacids (Compernolle and Müller, 2014), we assess the importance of the partitioning to the particulate phase for polyols in clouds and aqueous aerosol, approximating the liquid phase as a dilute aqueous solvent. Moreover, we also perform a sensitivity test, aiming at determining the particulate fraction of polyols, diacids and hydroxy polyacids in the case of an aqueous ammonium sulfate aerosol.

We note that this discussion, based on Henry's law, is only applicable if the organic compound is present in a tiny amount, and this may not be justified for all situations encountered in the lower atmosphere.

\subsection{Pure water as the solvent}

For clouds, the liquid water content (LWC) varies between typically 0.1 and $1 \mathrm{~g} \mathrm{~m}^{-3}$, and for aqueous aerosols between $10^{-6}$ and $10^{-4} \mathrm{~g} \mathrm{~m}^{-3}$ (Ervens et al., 2011). The particulate fraction of organic solute is equal to

$$
f_{\mathrm{p}, \mathrm{s}} \equiv \frac{n_{\mathrm{p}, \mathrm{s}}}{n_{\mathrm{p}, \mathrm{s}}+n_{\mathrm{g}, \mathrm{s}}}
$$

with $n_{\mathrm{p}, \mathrm{s}}, n_{\mathrm{g}, \mathrm{s}}$ the moles of solute in particulate and gas phase respectively. Using the ideal gas law, Eq. (19) can be transformed into

$$
f_{\mathrm{p}, \mathrm{s}}=\frac{1}{1+n_{\mathrm{g}, \mathrm{s}} / n_{p, s}}=\frac{1}{1+\frac{p_{s} V_{\mathrm{air}}}{\mathrm{RT}} \frac{1}{c_{s} V_{\mathrm{p}}}}
$$

with $V_{\text {air }}$ a unit volume of air and $V_{\mathrm{p}}$ the particle volume. If partitioning between gas and aqueous phase is governed solely by Henry's law (Eq. 1), and the solvent is considered pure water, Eq. (20) becomes

$$
f_{\mathrm{p}, \mathrm{s}}=\frac{1}{k^{*} / k_{h}+1}, \text { with } k^{*}=\frac{V_{\mathrm{air}}}{V_{\mathrm{s}}} \frac{1}{\mathrm{RT}}=\frac{\rho_{\mathrm{w}}}{\mathrm{LWC}} \frac{1}{\mathrm{RT}}
$$


Table 5. Henry's law constants and gas dissolution enthalpies at $298.15 \mathrm{~K}$ for the polyols considered in this work, from Eqs. (4, 5, 8, 10). $\gamma_{\mathrm{s}}^{\infty}$ is taken from Table 2, $p_{\mathrm{Cr}}^{0}, \Delta H_{\mathrm{sub}}$ from Table 3 and $\gamma_{\mathrm{s}}^{\infty} / \gamma_{\mathrm{s}}^{\text {sat }}$ from Table 4.

\begin{tabular}{|c|c|c|c|c|c|}
\hline \multirow[t]{2}{*}{ Molecule } & \multirow{2}{*}{$\frac{k_{h}}{\mathrm{Matm}^{-1}}$} & \multirow{2}{*}{$\frac{\Delta H_{\mathrm{g} \rightarrow \mathrm{aq}}^{\infty}}{\mathrm{kJ} \mathrm{mol}^{-1}}$} & \multicolumn{2}{|c|}{ Data source for Eqs. (4) and (5). } & \multirow{2}{*}{$\frac{k_{h}}{\mathrm{Matm}^{-1}}$} \\
\hline & & & $\begin{array}{c}p_{\mathrm{L}}^{0} \\
\Delta H_{\mathrm{vap}}\end{array}$ & $\begin{array}{c}\Delta H_{\mathrm{L} \rightarrow \mathrm{aq}}^{\infty}(\mathrm{L}) \\
\text { or } \Delta H_{\mathrm{Cr} \rightarrow \mathrm{aq}}^{\infty}(\mathrm{Cr})\end{array}$ & \\
\hline 1,2-ethane diol & $6.6 \times 10^{5}$ & -72.9 & $\mathrm{a}$ & $\mathrm{L}^{\mathrm{e}}$ & $4.1 \times 10^{5 j}$ \\
\hline 1,2-propane diol & $2.7 \times 10^{5}$ & -78.8 & $\mathrm{a}$ & $L^{f}$ & $1 \times 10^{5 \mathrm{k}}$ \\
\hline 1,3-propane diol & $1.6 \times 10^{6}$ & -79.1 & a & $\mathrm{L}^{\mathrm{e}}$ & $9.2 \times 10^{5 \mathrm{j}}$ \\
\hline 1,2-butane diol & $2.1 \times 10^{5}$ & -82.1 & a & $\mathrm{L}^{\mathrm{g}}$ & \\
\hline 1,3-butane diol & $7.1 \times 10^{5}$ & -84.5 & a & $L^{g}$ & \\
\hline 1,4-butane diol & $3.5 \times 10^{6}$ & -89.6 & a & $\mathrm{L}^{\mathrm{g}}$ & $1 \times 10^{5 \mathrm{k}}$ \\
\hline 2,3-butane diol & $1.1 \times 10^{5}$ & -82.2 & b & $L^{g}$ & $4 \times 10^{4 k}$ \\
\hline 1,2-pentane diol & $1.4 \times 10^{5}$ & & $\mathrm{a}$ & & \\
\hline 1,4-pentane diol & $2.3 \times 10^{6}$ & & $\mathrm{~b}$ & & \\
\hline 1,5-pentane diol & $7.1 \times 10^{6}$ & -103.5 & b & $\mathrm{L}^{\mathrm{e}}$ & \\
\hline 2,4-pentane diol & $3.9 \times 10^{5}$ & & & & \\
\hline 1,2-hexane diol & $1.7 \times 10^{5}$ & & a & & \\
\hline 2,5-hexane diol & $1.4 \times 10^{6}$ & & $\mathrm{~b}$ & & \\
\hline 1,7-heptane diol & $4.6 \times 10^{6}-8.4 \times 10^{6}$ & & $\mathrm{c}$ & & \\
\hline 1,9-nonane diol & $2.4 \times 10^{6}-4.0 \times 10^{6}$ & & & & \\
\hline 1,10-decane diol & $2.5 \times 10^{6}-3.0 \times 10^{6}$ & & & & \\
\hline glycerol & $4.8 \times 10^{8}$ & -92.6 & d & $L^{h}$ & $6 \times 10^{8 \mathrm{k}}$ \\
\hline erythritol & $1.1 \times 10^{12}$ & -133 & & $\mathrm{Cr}^{\mathrm{i}}$ & \\
\hline pentaerythritol & $7.4 \times 10^{12}$ & -133 & & $\mathrm{Cr}^{\mathrm{i}}$ & \\
\hline xylitol & $4.0 \times 10^{13}$ & -140 & & $\mathrm{Cr}^{\mathrm{i}}$ & \\
\hline adonitol & $4.7 \times 10^{13}$ & -147 & & $\mathrm{Cr}^{\mathrm{i}}$ & \\
\hline arabinitol & $6.8 \times 10^{13}$ & -147 & & $\mathrm{Cr}^{\mathrm{i}}$ & \\
\hline sorbitol & $6.7 \times 10^{16}$ & -181 & & $\mathrm{Cr}^{\mathrm{i}}$ & \\
\hline mannitol & $1.8 \times 10^{17}$ & -184 & & $\mathrm{Cr}^{\mathrm{i}}$ & \\
\hline dulcitol & $9.1 \times 10^{16}$ & -181 & & $\mathrm{Cr}^{\mathrm{i}}$ & \\
\hline
\end{tabular}

${ }^{a}$ Verevkin (2004), Verevkin (2007), Toktonov (2009). For 1,2-propane diol: Verevkin et al. (2009). ${ }^{\text {b }}$ Engineering Sciences Data Unit Ltd (1995).

${ }^{c} p_{\mathrm{L}}^{0}$ from either Piacente et al. (1994, 1993) (giving rise to the lower $k_{h}$ ) or Knauth and Sabbah (1990a) (giving rise to the higher $k_{h}$ ).

$p_{\mathrm{L}}^{0}$ is corrected to $298.15 \mathrm{~K}$ using $C_{p, \mathrm{~L}}$ data from Góralski and Tkaczyk (2008) and $C_{p, \mathrm{~g}}$ estimated with the method of Benson (1976),

but the effect is small. ${ }^{\mathrm{d}}$ Cammenga et al. (1977).

${ }^{\mathrm{e}}$ Nichols et al. (1976), ${ }^{\mathrm{f}}$ Matsumoto et al. (1977), ${ }^{\mathrm{g}}$ Lopes Jesus et al. (2000), ${ }^{\mathrm{h}}$ Bastos et al. (1988), ${ }^{\mathrm{i}}$ Jasra and Ahluwalia (1982).

j Bone et al. (1983), value at $293 \mathrm{~K} .{ }^{\mathrm{k}}$ Saxena and Hildemann (1996), value obtained from vapour-liquid equilibrium data.

with $\rho_{\mathrm{w}}$ the density of pure water. From the LWC range given above, and fixing $T$ to the reference temperature of $298.15 \mathrm{~K}$, it follows that for clouds, $k^{*}$ varies between $4 \times 10^{4}$ and $4 \times 10^{5} \mathrm{Matm}^{-1}$. From Table 5, it can be deduced that all polyols with three or more hydroxyl groups will be almost completely partitioned to the aqueous phase. Diols will be completely or partially in the aqueous phase, depending on the case. For aqueous aerosol, if one (falsely) assumes the aerosol phase to be pure water, it is obtained from the LWC range given above that at the reference temperature $k^{*}$ varies between $4 \times 10^{8}$ and $4 \times 10^{10} \mathrm{Matm}^{-1}$. With this assumption, diols will not partition appreciably to the aqueous phase, glycerol will partition to some extent, and only at the highest water content, while all polyols with four or more hydroxy groups should reside almost completely in the particulate phase.

\subsection{Aqueous ammonium sulfate aerosol as the solvent}

An aqueous aerosol is not a dilute aqueous solution, but is instead a concentrated mixture of organics and/or inorganics. HLC determined for a pure water solvent are less applicable to such mixtures. We present here a sensitivity test for a simple aerosol mixture of water and ammonium sulfate $\left(\left(\mathrm{NH}_{4}\right)_{2} \mathrm{SO}_{4}, \mathrm{AS}\right)$.

Note however that this test is only applicable to a situation with a tiny amount of organics. If e.g. a separate organic phase is present, less hydrophilic compounds may partition substantially to the particles, even if the HLC-based analysis suggests otherwise. 
It is more convenient to use here the alternative HLC definition $k_{h}^{p x}$ instead (Eq. 2). Let us define $n_{\mathrm{g}, \mathrm{s}}$ and $n_{\mathrm{p}, \mathrm{s}}$ as the number of moles of solute in gas and particulate phase respectively, and $n_{\mathrm{p} \text {,tot }}$ as the total number of moles of the solution. As the particulate solute mole fraction is equal to $n_{\mathrm{p}, \mathrm{s}} / n_{\mathrm{p} \text {,tot }}$, and using the ideal gas law, Eq. (2) can be transformed into

$k_{h}^{p x}=\lim _{n_{\mathrm{g}, \mathrm{s}}, n_{\mathrm{p}, \mathrm{s}} \rightarrow 0} \frac{n_{\mathrm{p}, \mathrm{s}} / n_{\mathrm{p}, \mathrm{tot}}}{\frac{n_{\mathrm{g}, \mathrm{s}}}{V_{\mathrm{air}}} \mathrm{RT}}=\left(\frac{f_{\mathrm{p}, \mathrm{s}}}{1-f_{\mathrm{p}, \mathrm{s}}}\right) \frac{V_{\mathrm{air}}}{n_{\mathrm{p}, \mathrm{tot}} \mathrm{RT}}$.

In the last step Eq. (19) was used. Eq. (22) can be rearranged to

$$
f_{\mathrm{p}, \mathrm{s}}=\frac{1}{1+\frac{1}{k_{h}^{p x} \mathrm{RT}} \frac{V_{\mathrm{air}}}{n_{\mathrm{p}, \mathrm{tot}}}}
$$

Note that in the particular case of the AS-water system

$n_{\mathrm{p}, \mathrm{tot}}=n_{\mathrm{p}, \mathrm{w}}+3 n_{\mathrm{p}, \mathrm{AS}}+n_{\mathrm{p}, \mathrm{s}}=n_{\mathrm{p}, \mathrm{w}}+3 n_{\mathrm{p}, \mathrm{AS}}$

as each molecule of AS dissociates into three ions, and the amount of organic solute is infinitesimally small.

The organic solutes considered are the polyols discussed in this work, and the diacids and hydroxy polyacids treated in our previous work (Compernolle and Müller, 2014). The $k_{h}^{p x}$ of a solute for a solvent consisting of water and a mole fraction $x_{\text {AS }}$ of dissolved AS can be calculated from

$$
\begin{aligned}
& k_{h}^{p x}\left(x_{\mathrm{AS}}\right)=k_{h}^{p x}\left(x_{\mathrm{AS}}=0\right) \frac{\gamma_{\mathrm{S}}^{\infty}\left(x_{\mathrm{AS}}=0\right)}{\gamma_{\mathrm{S}}^{\infty}\left(x_{\mathrm{AS}}\right)} \\
& =k_{h}^{p x}\left(x_{\mathrm{AS}}=0\right) \frac{1}{\gamma_{\mathrm{S}}^{*}}
\end{aligned}
$$

with $\gamma_{\mathrm{s}}^{*}$ the activity coefficient of the organic solute using the asymmetric convention (i.e. $\gamma^{*}=1$ if the solute is infinitely diluted in pure water). The $k_{h}^{p x}\left(x_{\mathrm{AS}}=0\right)$ was taken from Table 5 or Table 3 of Compernolle and Müller (2014) (recommended values only), after the appropriate conversion $k_{h}^{p x}=$ $c_{\mathrm{W}} k_{h}$. The $\gamma_{\mathrm{s}}^{\infty}\left(x_{\mathrm{AS}}\right)$ and $\gamma_{\mathrm{s}}^{\infty}\left(x_{\mathrm{AS}}=0\right)$ were calculated with the model AIOMFAC (Zuend et al., 2011), available online (http://www.aiomfac.caltech.edu). This model calculates activity coefficients taking interactions between water, organics and inorganics into account. A very small organic mole fraction $\left(x_{\mathrm{org}}=10^{-10}\right)$ was chosen to ensure that $\gamma_{\mathrm{S}}^{\infty}\left(x_{\mathrm{AS}}\right)$ and $\gamma_{\mathrm{S}}^{\infty}\left(x_{\mathrm{AS}}=0\right)$ represent IDACs. As a consequence, the impact of the organic solute on the activities of water and the ions is negligible. Although the activities are estimated and not measured, we note that activity data sets of several AS-water-organic mixtures (organic being a polyol, diacid or hydroxy polyacid) are used to determine AIOMFAC's parameters (Zuend et al., 2011).

Given a particular $x_{\mathrm{AS}}$, the water activity and hence the relative humidity $(\mathrm{RH})$ are fixed by the AIOMFAC model. $x_{\mathrm{AS}}$ was varied between 0.43 and 0 , corresponding to a $\mathrm{RH}$ range between 30 and $100 \%$. Note that pure AS particles have a deliquescence $\mathrm{RH}(\mathrm{DRH})$ of $79.5 \%$ and an efflorescence RH (ERH) of $\sim 35 \%$ (Martin, 2000). The DRH is the equilibrium point below which solid AS is the thermodynamically stable phase and this corresponds to the solubility limit of AS in water. However, depending on the RH history of the particle, a metastable supersaturated solution may instead be present below the DRH. Below the ERH, only solid AS is present in the particulate phase.

The particulate fraction $f_{\mathrm{p}, \mathrm{s}}$ of the organic solute depends on the amount of solvent (water $+\mathrm{AS}$ ) per volume of air. A fixed AS mass concentration of $4 \mu \mathrm{g} \mathrm{m}^{-3}$ was chosen, typical for inorganic aerosols at mid-latitudes over continents (http://vista.cira.colostate.edu/improve/). As a consequence, upon increasing $\mathrm{RH}$ from the ERH to $90 \%$, the LWC varies between $10^{-6}$ and $10^{-5} \mathrm{~g} \mathrm{~m}^{-3}$, a typical range for aqueous aerosol.

Polyols. Due to their low $k_{h}$, diols do not partition significantly to aqueous aerosol and hence are not included in this analysis. Stereo isomers of xylitol and sorbitol were also not included, given their similar $k_{h}$ and the fact that AIOMFAC does not distinguish between stereo isomers. For the polyols, AIOMFAC predicts an activity increase with lowering $\mathrm{RH}$ (or equivalently increasing the salt concentration) (Fig. 2a). The effect increases with the number of hydroxyl groups. However, this is more than compensated by the concomitant increase in $k_{h}\left(x_{\mathrm{AS}}=0\right)$ (Table 5). The particulate fraction of polyols decreases with decreasing $\mathrm{RH}$ both due to the increase in solute activity, and the decrease of total absorbing mass. At $\mathrm{RH}=90 \%$ glycerol, with three hydroxyl groups, is $95 \%$ in the gas phase while sorbitol, with six hydroxyl groups, is still $50 \%$ in the particulate phase at $\mathrm{RH}=44 \%$. This is due to the large difference ( 8 orders of magnitude) of their $k_{h}$ values.

Linear diacids. Diacids with two (oxalic) up to 10 (sebacic) carbon atoms are considered. Let us neglect acid dissociation for the moment. AIOMFAC's interaction parameters are negative (stabilizing) between the carboxylic acid group $\mathrm{COOH}$ on the one hand, and the ions $\mathrm{NH}_{4}^{+}$and $\mathrm{SO}_{4}^{2-}$ on the other hand. For the group $\mathrm{CH}_{2}$, these interaction parameters are positive (destabilizing). As a consequence, the activity of the linear diacids with four carbon atoms or more increases with decreasing RH. The activity of oxalic acid, on the other hand, decreases with decreasing $\mathrm{RH}$, while the activity of malonic acid stays roughly constant. Even without taking acid dissociation into account, it is clear that these diacids partition appreciably to the particulate phase (Fig. 2b). Note that for malonic acid, we chose the lower of the recommended $k_{h}$ values from Table 3 of Compernolle and Müller (2014); the higher value would lead to $f_{\mathrm{p}}$ near unity even without acid dissociation.

Hydroxy polyacids. Citric and tartaric acid exhibit a modest activity increase upon decrease of the RH. On the other hand, they have extremely high $k_{h}\left(x_{\mathrm{AS}}=0\right)$ values (Compernolle and Müller, 2014). Therefore, they will reside almost 
Table 6. Activity coefficient methods that best fit the data of Marcolli and Peter (2005). For seven compounds, an alternative fitting is presented.

\begin{tabular}{|c|c|c|c|c|c|c|c|}
\hline Molecule & Fitting method & $A_{12}, A_{21}{ }^{\mathrm{a}}$ & $\ln \gamma_{\mathrm{S}}^{\infty}$ & $\operatorname{SD}\left(\ln \gamma_{\mathrm{W}}\right)^{\mathrm{b}}$ & $\mathrm{SD}\left(a_{\mathrm{W}}\right)^{\mathrm{c}}$ & $\Delta_{\text {syst }} \mathrm{d}$ & $\sigma_{\text {rand }} \mathrm{e}$ \\
\hline 1,2-ethane diol & Margules & $-0.13,-0.38$ & -0.38 & 0.0094 & 0.0033 & \pm 0.02 & 0.07 \\
\hline 1,2-propane diol & Margules & $0.038,0.078$ & 0.078 & 0.0098 & 0.0053 & \pm 0.03 & 0.05 \\
\hline 1,3-propane diol & UNIQUAC & $-144.83,207.56$ & 0.22 & 0.0064 & 0.0033 & \pm 0.02 & 0.06 \\
\hline \multirow[t]{2}{*}{ 1,2-butane diol } & Van Laar & $0.40,1.32$ & 1.32 & 0.0085 & 0.0039 & \pm 0.04 & 0.08 \\
\hline & UNIQUAC & $-75.45,217.72$ & 1.43 & 0.0087 & 0.0044 & & \\
\hline \multirow[t]{2}{*}{ 1,3-butane diol } & Wilson & $1.84,0.22$ & 0.68 & 0.0101 & 0.0053 & \pm 0.05 & 0.13 \\
\hline & Margules & $0.12,0.48$ & 0.48 & 0.0107 & 0.0053 & & \\
\hline \multirow[t]{2}{*}{ 1,4-butane diol } & Wilson & $2.00,0.18$ & 0.75 & 0.0083 & 0.0035 & \pm 0.04 & 0.11 \\
\hline & UNIQUAC & $-103.07,199.15$ & 0.86 & 0.0090 & 0.0045 & & \\
\hline 2,3-butane diol & Margules & $0.26,0.57$ & 0.57 & 0.0061 & 0.0030 & \pm 0.03 & 0.03 \\
\hline \multirow[t]{2}{*}{ 1,5-pentane diol } & Van Laar & $0.37,1.66$ & 1.66 & 0.0126 & 0.0046 & \pm 0.02 & 0.14 \\
\hline & UNIQUAC & $-60.77,201.91$ & 1.73 & 0.0127 & 0.0050 & & \\
\hline 1,2-pentane diol & UNIQUAC & $9.40,152.56$ & 2.48 & 0.0125 & 0.0053 & \pm 0.03 & 0.08 \\
\hline \multirow[t]{2}{*}{ 1,4-pentane diol } & Wilson & $1.70,0.13$ & 1.33 & 0.0107 & 0.0053 & \pm 0.06 & 0.098 \\
\hline & Van Laar & $0.35,1.29$ & 1.29 & 0.0108 & 0.0051 & & \\
\hline 2,4-pentane diol & Margules & $0.20,1.04$ & 1.04 & 0.0111 & 0.0073 & \pm 0.03 & 0.02 \\
\hline \multirow[t]{2}{*}{ 1,2-hexane diol } & Van Laar & $0.63,3.27$ & 3.27 & 0.0041 & 0.0033 & \pm 0.05 & 0.09 \\
\hline & UNIQUAC & $13.44,185.39$ & 3.19 & 0.0063 & 0.0050 & & \\
\hline \multirow[t]{2}{*}{ 2,5-hexane diol } & Van Laar & $0.37,1.74$ & 1.74 & 0.0153 & 0.0080 & \pm 0.06 & 0.10 \\
\hline & Wilson & $1.75,0.07$ & 1.90 & 0.0158 & 0.0089 & & \\
\hline 1,7-heptane diol & UNIQUAC & $-4.99,206.56$ & 3.34 & 0.0158 & 0.0072 & \pm 0.04 & 0.06 \\
\hline
\end{tabular}

${ }^{\mathrm{a} O p t i m i z e d ~ p a r a m e t e r s ~ t o ~ u s e ~ i n ~ t h e ~ a c t i v i t y ~ c o e f f i c i e n t ~ e x p r e s s i o n ~ f o r ~} \ln \gamma_{\mathrm{w}} \cdot{ }^{\mathrm{b}}$ Standard deviation between modelled and observed $\ln \gamma_{\mathrm{w}} \cdot{ }^{\mathrm{c}}$ Standard deviation between modelled and observed $a_{\mathrm{W}} .{ }^{\mathrm{d}}$ Range for $\ln \gamma_{\mathrm{S}}{ }^{\infty}$, obtained by applying systematic shifts of \pm 0.005 to the $a_{\mathrm{W}}$ data. ${ }^{\mathrm{e}}$ Standard deviation on $\ln \gamma_{\mathrm{S}}^{\infty}$, obtained by applying random shifts from a normal distribution with $\sigma=0.0075$ to the $a_{\mathrm{W}}$ data.

completely in the particulate phase from $\mathrm{RH}=100 \%$ to the ERH.

Impact of acid dissociation. The effective HLC, $k_{h}^{p x \text {, eff }}$, of a polyacid is larger than $k_{h}^{p x}$ due to acid dissociation. For a diacid one has

$k_{h}^{p x, \text { eff }}=\lim _{x_{\mathrm{H}_{2} \mathrm{~A}}, x_{\mathrm{HA}^{-}}, x_{\mathrm{A}^{2-}}, p_{\mathrm{H}_{2} \mathrm{~A}} \rightarrow 0} \frac{x_{\mathrm{H}_{2} \mathrm{~A}}+x_{\mathrm{HA}^{-}}+x_{\mathrm{A}^{2-}}}{p_{\mathrm{H}_{2} \mathrm{~A}}}$

with $x_{\mathrm{H}_{2} \mathrm{~A}}, x_{\mathrm{HA}^{-}}$and $x_{\mathrm{A}^{2-}}$ the mole fractions of the undissociated acid, monodissociated acid and twice dissociated acid respectively. Acid dissociation is governed by the acid dissociation constants

$$
\begin{aligned}
K_{\mathrm{a}, 1} & =\frac{\gamma_{\mathrm{H}^{+}}{ }^{*} x_{\mathrm{H}^{+}} \gamma_{\mathrm{HA}^{-}}{ }^{*} x_{\mathrm{HA}^{-}}}{\gamma_{\mathrm{H}_{2} \mathrm{~A}^{*} x_{\mathrm{H}_{2} \mathrm{~A}}}} \\
K_{\mathrm{a}, 2} & =\frac{\gamma_{\mathrm{H}^{+}}{ }^{*} x_{\mathrm{H}^{+}} \gamma_{\mathrm{A}^{2-}}{ }^{*} x_{\mathrm{A}^{2-}}}{\gamma_{\mathrm{HA}^{-}}{ }^{*} x_{\mathrm{HA}^{-}}}
\end{aligned}
$$

with $K_{\mathrm{a}, i}$ mole fraction based acid dissociation constants, and $\gamma^{*}$ mole fraction based activity coefficients, with the asymmetric convention (i.e. becoming unity at infinite dilu- tion in pure water). Combining Eqs. (26) and (27) leads to

$k_{h}^{p x, \text { eff }}=k_{h}^{p x}$

$\left(1+K_{\mathrm{a}, 1} \frac{\gamma_{\mathrm{H}_{2} \mathrm{~A}}{ }^{*}}{\gamma_{\mathrm{HA}^{-}}} \frac{1}{\gamma_{\mathrm{H}^{+}}{ }^{*} x_{\mathrm{H}^{+}}}+K_{\mathrm{a}, 1} K_{\mathrm{a}, 2} \frac{\gamma_{\mathrm{H}_{2} \mathrm{~A}}}{\gamma_{\mathrm{A}^{2-}}}\left(\frac{1}{\gamma_{\mathrm{H}^{+}}{ }^{*} x_{\mathrm{H}^{+}}}\right)^{2}\right)$.

AIOMFAC does not calculate activity coefficients of ionized organic acids. To describe the ionization in the water-ASdiacid system, we used the models provided at the site of EAIM (http://www.aim.env.uea.ac.uk/aim/aim.php). Specifically, model IV was used, which is an implementation of the parameterizations of Friese and Ebel (2010) and (for the diacids) of Clegg and Seinfeld (2006). Solid formation was prevented, and the dissociation equilibria $\mathrm{H}_{2} \mathrm{O} / \mathrm{OH}^{-}$, $\mathrm{NH}_{4}^{+} / \mathrm{NH}_{3}, \mathrm{HSO}_{4}^{-} / \mathrm{SO}_{4}^{2-}$ were taken into account. At the vanishingly small acid concentration used, E-AIM calculates the same $\gamma_{\mathrm{H}_{2} \mathrm{~A}}{ }^{*}, \gamma_{\mathrm{HA}^{-}}{ }^{*}$ and $\gamma_{\mathrm{A}^{2-}}{ }^{*}$ regardless of the identity of the diacid. This is not realistic; one expects a larger $\gamma^{*}$ value for a diacid with more $\mathrm{CH}_{2}$ groups. Therefore, $\gamma_{\mathrm{H}_{2}} \mathrm{~A}^{*}$, equal to $\gamma_{\mathrm{S}}^{*}$ in Eq. (25), is still calculated by AIOMFAC, to take into account the destabilizing $\mathrm{CH}_{2}$-ion interaction. The $\gamma_{\mathrm{H}^{+}}{ }^{*} x_{\mathrm{H}^{+}}, \frac{\gamma_{\mathrm{H}_{2} \mathrm{~A}^{*}}}{\gamma_{\mathrm{HA}^{-}}{ }^{*}}$ and $\frac{\gamma_{\mathrm{H}_{2} \mathrm{~A}^{*}}}{\gamma_{\mathrm{A}^{2-}}{ }^{*}}$ in Eq. (28) are determined by the E-AIM calculation. Note that due to the vanishingly small acid concentration, $\gamma_{\mathrm{H}^{+}}{ }^{*} x_{\mathrm{H}^{+}}$is determined by the amounts of water and AS only. Acid dissociation constants were taken from E-AIM or Apelblat (2002). Oxalic and malonic acid 

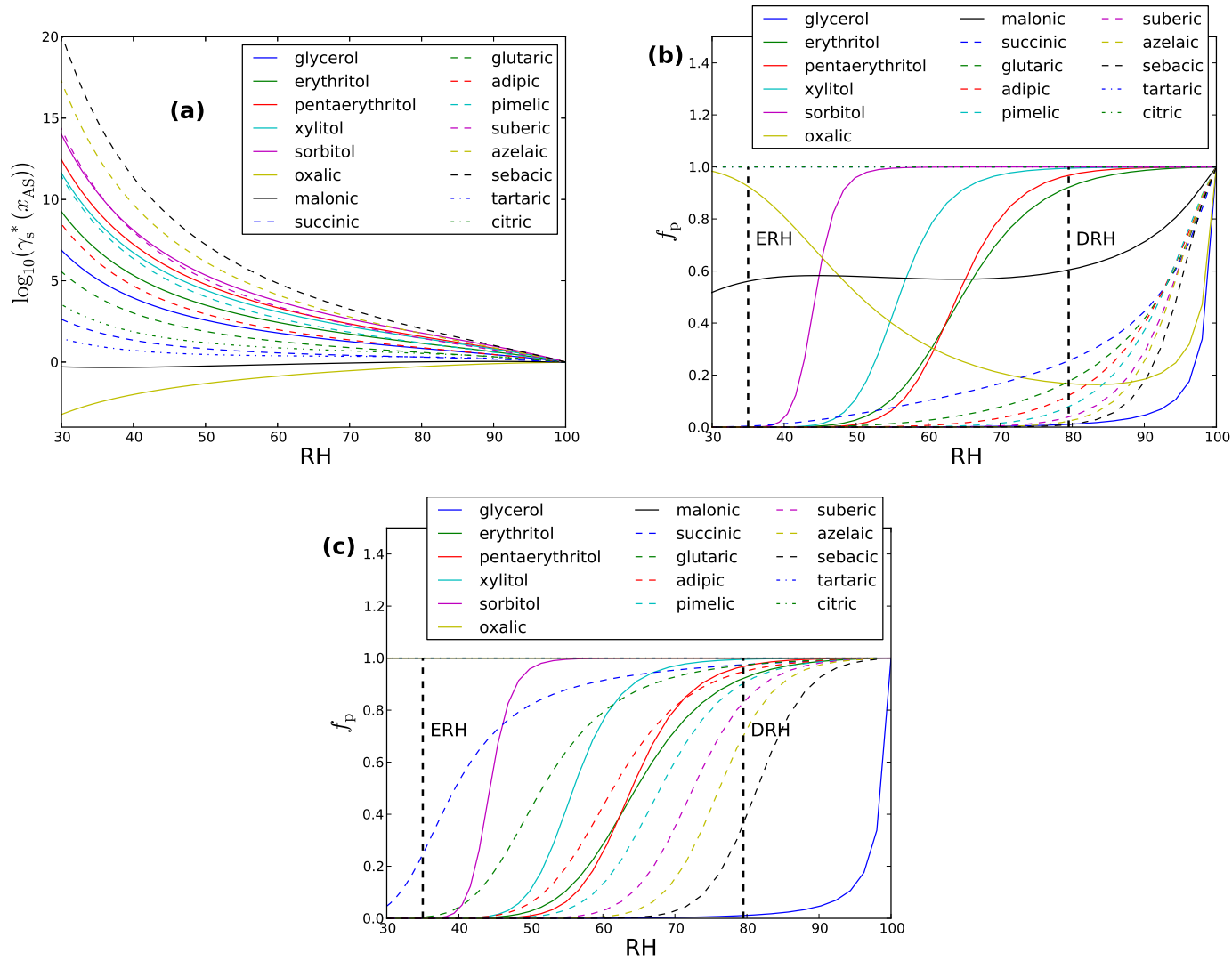

Figure 2. (a) Activity coefficient correction $\left(\log _{10} \gamma_{\mathrm{s}}^{*}\right)$ of the organic solute vs. RH for an AS-water particle, as calculated by AIOMFAC. (b) Particulate fraction of the organic solute vs. RH. Acid dissociation is not taken into account. Tartaric and citric acid have $f_{\mathrm{p}}=1$ over the entire presented range. (c), as (b), but taking acid dissociation into account using the on-line model of E-AIM (see text for more details). Oxalic, malonic, tartaric and citric acid have $f_{\mathrm{p}}=1$ over the entire presented range.

are predicted to be completely in the aqueous phase from $\mathrm{RH}=100 \%$ to the ERH, while the particulate fraction of the other diacids are clearly enhanced (Fig. 2c), compared to the calculation without acid dissociation (Fig. 2b).

\section{Discussion and conclusions}

\subsection{Assessing main uncertainties}

HLC of polyols with 2-6 hydroxy groups are derived in this work, using experimental data and thermodynamic relationships. This study complements a previous work (Compernolle and Müller, 2014) where the focus was on diacids and hydroxy polyacids.

An error analysis is performed in Appendix A. The compounds that are liquid at room temperature (most diols and glycerol) have a relatively low uncertainty in $k_{h}$ (relative standard error 6-28\%, see Table 7). For some compounds, further improvement is possible with more precise $p_{\mathrm{L}}^{0}$ data and/or more fine-grained and precise $a_{\mathrm{w}}$ data in the dilute region.
Table 7. Estimated relative standard errors on $p_{\mathrm{L}}^{0}, \gamma_{\mathrm{S}}^{\infty}$ and the resulting relative standard error on $k_{h}$. See Sects. A1 and A2.

\begin{tabular}{lccc}
\hline Molecule & $\mathrm{SE}\left(p_{\mathrm{L}}^{0}\right)$ & $\frac{\mathrm{SE}\left(\gamma_{\mathrm{s}}^{\infty}\right)}{p_{\mathrm{L}}^{0}}$ & $\frac{\mathrm{SE}\left(k_{h}\right)}{\gamma_{h}^{\infty}}$ \\
\hline 1,2-ethane diol & 0.03 & 0.05 & 0.06 \\
1,2-propane diol & 0.03 & 0.05 & 0.06 \\
1,3-propane diol & 0.03 & 0.05 & 0.06 \\
1,2-butane diol & 0.03 & 0.05 & 0.06 \\
1,3-butane diol & 0.03 & 0.05 & 0.06 \\
1,4-butane diol & 0.03 & 0.05 & 0.06 \\
2,3-butane diol & 0.25 & 0.05 & 0.25 \\
1,2-pentane diol & 0.03 & 0.13 & 0.13 \\
1,4-pentane diol & 0.25 & 0.13 & 0.28 \\
1,5-pentane diol & 0.25 & 0.05 & 0.25 \\
2,4-pentane diol & 0.03 & 0.13 & 0.13 \\
1,2-hexane diol & 0.03 & 0.13 & 0.13 \\
2,5-hexane diol & 0.25 & 0.13 & 0.28 \\
1,7-heptane diol & 0.25 & 0.13 & 0.28 \\
glycerol & 0.03 & 0.05 & 0.06 \\
\hline
\end{tabular}


Table 8. Estimated relative standard errors on $x_{\mathrm{s}}^{\text {sat }}, \frac{\gamma_{\mathrm{s}}^{\infty}}{\gamma_{\mathrm{s}}^{\text {sat }}}$ and the various parts of $p_{\mathrm{Cr}}^{0}$, and the derived relative standard error on $k_{h}$. See Sects. A3, A4 and A5.

\begin{tabular}{|c|c|c|c|c|c|c|c|c|}
\hline & $\frac{\mathrm{SE}\left[x_{\mathrm{s}}^{\mathrm{sat}}\right]}{x_{\mathrm{s}}^{\mathrm{sat}}}$ & $\frac{\operatorname{SE}\left[\frac{\gamma_{\mathrm{S}}^{\infty}}{\gamma_{\mathrm{s}}^{\text {sat }}}\right]}{\frac{\gamma_{\mathrm{s}}^{\infty}}{\gamma_{\mathrm{s}}^{\text {sat }}}}$ & $\frac{T_{\text {fus }}}{\mathrm{K}}$ & $\mathrm{SE}(C)$ & $\frac{T_{\text {meas }}}{\mathrm{K}}$ & $\operatorname{SE}(A)$ & $\operatorname{SE}(B)$ & $\frac{\mathrm{SE}\left[k_{h}\right]}{k_{h}}$ \\
\hline 1,9-nonane diol & 0.16 & 0 & $318.7^{\mathrm{g}}$ & 0.13 & $\begin{array}{l}323^{b} \\
360^{c}\end{array}$ & $\begin{array}{l}0.27 \\
0.35\end{array}$ & $\begin{array}{l}0.01 \\
0.06\end{array}$ & $\begin{array}{l}0.34 \\
0.41\end{array}$ \\
\hline 1,10-decane diol & 0.16 & 0 & $345.8^{\mathrm{g}}$ & 0.18 & $\begin{array}{l}342^{b} \\
364^{c}\end{array}$ & $\begin{array}{l}0.31 \\
0.36\end{array}$ & $\begin{array}{l}0.03 \\
0.07\end{array}$ & $\begin{array}{l}0.39 \\
0.44\end{array}$ \\
\hline erythritol & 0.05 & 0 & $\begin{array}{c}390.25^{\mathrm{h}} \\
\mathrm{a}\end{array}$ & $\begin{array}{c}0.23 \\
\mathrm{a}\end{array}$ & $\begin{array}{l}412^{\mathrm{d}} \\
386^{\mathrm{e}}\end{array}$ & $\begin{array}{l}0.46 \\
0.41\end{array}$ & $\begin{array}{l}0.2 \\
0.1\end{array}$ & $\begin{array}{l}0.55 \\
0.42\end{array}$ \\
\hline pentaerythritol & 0.05 & 0 & $\mathrm{a}$ & $\mathrm{a}$ & $\begin{array}{l}436^{\mathrm{d}} \\
404^{\mathrm{e}} \\
394^{\mathrm{f}}\end{array}$ & $\begin{array}{l}0.51 \\
0.45 \\
0.42\end{array}$ & $\begin{array}{l}0.28 \\
0.17 \\
0.14\end{array}$ & $\begin{array}{l}0.58 \\
0.48 \\
0.44\end{array}$ \\
\hline xylitol & 0.05 & 0.05 & $369.04^{\mathrm{h}}$ & 0.19 & $433^{d}$ & 0.51 & 0.27 & 0.61 \\
\hline adonitol & 0.05 & 0.16 & $369.08^{\mathrm{h}}$ & 0.20 & $443^{\mathrm{d}}$ & 0.52 & 0.31 & 0.66 \\
\hline arabinitol & 0.05 & 0.16 & $379.4^{\mathrm{d}}$ & 0.21 & $440^{\mathrm{d}}$ & 0.52 & 0.29 & 0.65 \\
\hline sorbitol & 0.05 & 0.05 & $366.5^{\mathrm{h}}$ & 0.18 & $477^{\mathrm{d}}$ & 0.59 & 0.44 & 0.76 \\
\hline mannitol & 0.05 & 0 & $437.25^{\mathrm{h}}$ & 0.30 & $477^{\mathrm{d}}$ & 0.59 & 0.44 & 0.80 \\
\hline dulcitol & 0.05 & 0 & $460.3^{\mathrm{d}}$ & 0.33 & $482^{\mathrm{d}}$ & 0.59 & 0.46 & 0.82 \\
\hline
\end{tabular}

a Fusion point and $\mathrm{SE}(C)$ not relevant here as $T_{\text {fus }}>T_{\text {meas }}$

b-h The same references as for Table 3 apply.

The compounds that are solid at room temperature, especially the polyols with four or more hydroxy groups, bear a much larger uncertainty in $k_{h}$ (relative standard error 34$82 \%$, see Table 8 ). This is mainly due to the use of hightemperature liquid or solid state vapour pressures. More specifically, it is due to the uncertainty in $\Delta H_{\text {vap }}$ or $\Delta H_{\text {sub }}$ in combination with the extrapolation over a large temperature interval. For the hexols, also the uncertainty in heat capacity becomes important, although we note that the error in $C_{p, \mathrm{~g}}$ is speculative as this property is estimated. Measuring the (solid or liquid state) vapour pressure closer to room temperature will lower these uncertainties.

As noted above, the $C_{p, \mathrm{~g}}$ values are estimated. Improvement here is possible by using $C_{p, \mathrm{~g}}$ derived from experiment or from ab initio calculations rather than using a group contribution method. For nonane diol and decane diol, only solubilities from a secondary reference (Merck Millipore) could be retrieved, for which it is difficult to estimate the reliability. New solubility measurements are desirable to obtain a more reliable $k_{h}$ estimate.

\subsection{Comparison with literature}

HLC compilations of polyols are provided by e.g. Sander (1999) and Saxena and Hildemann (1996). However, most values in these studies are estimated. Bone et al. (1983) provide HLC measurements for 1,2-ethane diol and 1,3-propane diol (Table 5). Their values are lower but reasonably close (within a factor of 2) to ours. While the majority of HLC values of polyols provided by Saxena and Hildemann (1996) are estimated, a few are derived from vapour-liquid equilibrium data. For 1,2-propane diol, 2,3-butane diol and glycerol, their HLC values are within a factor 3, but for 1,4-butane diol the difference is more than an order of magnitude. In conclusion, for five out of six HLC values, we have a reasonable agreement with the literature values.

The estimated values presented by Saxena and Hildemann (1996) are obtained by a group-contribution method (Suzuki et al., 1992) (values not reproduced in Table 5). For the diols, overestimations by $\sim 1$ order of magnitude compared to our values are common. For the compounds with three or more hydroxyl groups, the overestimation ranges between 3 (glycerol) and 8 (mannitol) orders of magnitude, showing the limitations of such an estimation method.

\subsection{Atmospheric implications}

According to the HLC derived in this and the previous work (Compernolle and Müller, 2014), diols will be partially (e.g. 1,2 hexane diol, depending on the droplet size) or completely (e.g. 1,4-butane diol) in the aqueous phase in clouds, while polyols with three or more hydroxyl groups, diacids and hydroxy polyacids will be completely in the aqueous phase. Regarding aqueous aerosol, the sensitivity test performed here using aqueous AS aerosol indicates that polyols with four or more hydroxyl groups are significantly or totally in the particulate phase, depending on the RH. The same holds for the longer linear diacids (succinic and higher). The shorter linear diacids (oxalic and malonic) and the hydroxy polyacids (citric and tartaric) are completely in the particu- 
Table 9. $p_{\mathrm{L}}^{0}$ calculations for erythritol, xylitol and sorbitol, with three vapour pressure estimation methods (Nannoolal et al., 2008; Moller et al., 2008; Myrdal and Yalkowsky, 1997) available at http://www.aim.env.uea.ac.uk/aim/aim.php.

\begin{tabular}{lcccc}
\hline method & & erythritol & xylitol & sorbitol \\
\hline Nannoolal & $T_{\mathrm{b}} / \mathrm{K}$ adj. & 612 & 634 & 674 \\
& $p_{\mathrm{L}}^{0}\left(T_{\text {ref }}\right) / \mathrm{Pa}$ & $2.2 \times 10^{-5}$ & $3.0 \times 10^{-7}$ & $2.5 \times 10^{-10}$ \\
Moller & $T_{\mathrm{b}} / \mathrm{K}$ adj. & 649 & 705 & 787 \\
& $p_{\mathrm{L}}^{0}\left(T_{\text {ref }}\right) / \mathrm{Pa}$ & $1.5 \times 10^{-5}$ & $2.6 \times 10^{-7}$ & $1.8 \times 10^{-10}$ \\
Myrdal-Yalkowsky & $T_{\mathrm{b}} / \mathrm{K}$ adj. & 656 & 703 & 772 \\
& $p_{\mathrm{L}}^{0}\left(T_{\text {ref }}\right) / \mathrm{Pa}$ & $9.7 \times 10^{-5}$ & $5.2 \times 10^{-6}$ & $5.9 \times 10^{-8}$ \\
\hline
\end{tabular}

${ }^{\text {a }}$ Hypothetical boiling point, adjusted such that the experimental $p_{\mathrm{L}}^{0}$ at $T_{\text {meas }}$ (Barone et al., 1990) is reproduced. These experimental $\left(T_{\text {meas }} / \mathrm{K}, p_{\mathrm{L}}^{0} / \mathrm{Pa}\right)$ data points are $(412,8.6),(433,5.5)$ and $(477,6.8)$ for erythritol, xylitol and sorbitol respectively.

late phase both at lower and higher $\mathrm{RH}$, due to (i) their relatively high acid dissociation constants and/or (ii) stabilizing or only mildly destabilizing interactions with AS and/or (iii) very high $k_{h}$ values.

Note that this analysis is only applicable for aqueous AS aerosol in the limiting case of a small concentration of organics. If e.g. a separate organic phase is present in the aerosol, partitioning to this phase should be taken into account as well.

Bao et al. (2012) measured gas particle partitioning of diacids at a site in Japan in different seasons. According to this study, both particulate and gaseous fractions are significant, and RH influences the partitioning. Xie et al. (2014) measured gas particle partitioning of 2-methyl tetrols at a site in Denver and found about equal particulate and gaseous fractions. Our sensitivity test, based on a simple AS-water aerosol system, cannot be quantitatively compared with these studies, but does show that partitioning to the particulate phase is important for diacids and tetrols. 


\section{Appendix A: Error analysis}

In this section we identify the main uncertainties contributing to the $k_{h}$ values, as well as the overall uncertainty. From the error propagation rule (Bevington, 2003), and Eqs. (4) and (8), the standard error (SE) on $k_{h}$ can be derived:

$$
\begin{aligned}
& \frac{\mathrm{SE}\left[k_{h}\right]}{k_{h}} \approx \sqrt{\left(\frac{\mathrm{SE}\left[p_{\mathrm{L}}^{0}\right]}{p_{L}^{0}}\right)^{2}+\left(\frac{\mathrm{SE}\left[\gamma_{\mathrm{s}}^{\infty}\right]}{\gamma_{\mathrm{s}}^{\infty}}\right)^{2}} \\
& \frac{\mathrm{SE}\left[k_{h}\right]}{k_{h}} \approx \sqrt{\left(\frac{\mathrm{SE}\left[p_{\mathrm{Cr}}^{0}\right]}{p_{\mathrm{Cr}}^{0}}\right)^{2}+\left(\frac{\mathrm{SE}\left[x_{\mathrm{s}}^{\mathrm{sat}}\right]}{x_{\mathrm{s}}^{\mathrm{sat}}}\right)^{2}+\left(\frac{\mathrm{SE}\left[\frac{\gamma_{\mathrm{s}}^{\infty}}{\gamma_{\mathrm{s}}^{\mathrm{sat}}}\right]}{\frac{\gamma_{\mathrm{s}}^{\infty}}{\gamma_{\mathrm{s}}^{\mathrm{sat}}}}\right)^{2}} .
\end{aligned}
$$

In Eq. (A2), the covariance between $x_{\mathrm{s}}^{\text {sat }}$ and $\gamma_{\mathrm{s}}^{\infty} / \gamma_{\mathrm{s}}^{\text {sat }}$ is neglected. Such covariance exists in principle, as $x_{\mathrm{s}}^{\text {sat }}$ enters the formula for deriving $\gamma_{\mathrm{s}}^{\infty} / \gamma_{\mathrm{s}}^{\text {sat }}$ (Eq. 18). However, due to the low error on $x_{\mathrm{s}}^{\text {sat }}$ (see Sect. A3), this can be neglected. Note that it also follows from the error propagation rule (Bevington, 2003) that $\frac{\mathrm{SE}[u]}{u}=\mathrm{SE}[\ln u]$.

We tried to obtain the uncertainties from the original studies. This is hindered by the fact that these errors are not always reported, or it is not always made clear what they exactly represent (e.g. once or twice the standard deviation). Discrepancies between results of different research groups are often larger than the reported errors of individual studies. Our error analysis is mostly based on this inter-laboratory error.

From Eqs. (A1) and (A2), it is clear that relative standard errors (i.e. SE $[u] / u$ ) are relevant. They are cited in the text as percentages. To estimate how much data of two data sources 1 and 2 disagree, we calculated the root mean squared relative difference (RMSRD)

$$
\operatorname{RMSRD}=\sqrt{\frac{1}{N} \sum_{i=1}^{N}\left(2 \frac{u_{1, i}-u_{2, i}}{u_{1, i}+u_{2, i}}\right)^{2}}
$$

with $u$ representing a physical quantity and $i$ running over $N$ data points (obtained by varying e.g. the temperature, the water content, or the molecule type). If we can consider the data of source 1 as more reliable than of source 2, the RMSRD is used to assign a relative standard error to source 2. Otherwise the RMSRD is assigned as relative standard error to both data sources.

Sometimes the absolute error is more relevant. To quantify the difference between two data sources, we use therefore the mean deviation (MD) and the root mean squared difference
(RMSD):

$$
\begin{aligned}
& \mathrm{MD}=\frac{1}{N} \sum_{i=1}^{N}\left(u_{1, i}-u_{2, i}\right) \\
& \mathrm{RMSD}=\sqrt{\frac{1}{N} \sum_{i=1}^{N}\left(u_{1, i}-u_{2, i}\right)^{2} .}
\end{aligned}
$$

An example where the absolute error is more relevant is for water activity data $a_{\mathrm{w}}$ in function of water content, which is used as input to calculate $\gamma_{\mathrm{s}}^{\infty}$ and $\gamma_{\mathrm{s}}^{\infty} / \gamma_{\mathrm{s}}^{\text {sat }}$ (Sects. A2 and A3). Of course $a_{\mathrm{w}}$ of both data sources was evaluated at the same water content, with interpolation of data points if necessary.

\section{A1 Liquid vapour pressure}

Verevkin (2007, 2004); Verevkin et al. (2009); Toktonov (2009) provide the bulk of $p_{\mathrm{L}}^{0}$ data for diols used in Table 5 (eight compounds in total). They report that their measurements are "reliable within 1-3\%" and point to a good consistency with other literature data. An additional advantage is that the measurements are performed at or near room temperature. We consider the data of this group the most reliable for diols - based on our experience with other vapour pressure data of this group, e.g. on aldehydes (Verevkin et al., 2003) and mono-alcohols (Kulikov et al., 2001; Verevkin and Schick, 2007) - and will use the data as a benchmark for other $p_{\mathrm{L}}^{0}$ data of diols. Regarding the triol glycerol, Cammenga et al. (1977) reports an accuracy of "somewhat less" than $0.6 \%$ and the authors state consistency with other work. Their measurements also include room temperature. We consider this work as reliable as well. We assign to all $p_{\mathrm{L}}^{0}$ data with label "a" and "d" in Table 5 a relative standard error of $2 \%$.

The $p_{\mathrm{L}}^{0}$ data of four diols used in Table 5 are from the compilation Engineering Sciences Data Unit Ltd (1995). Comparing $p_{\mathrm{L}}^{0}$ data of a set of eight diols with measurements of Verevkin and co-workers (which we consider more reliable), we find a RMSRD of $25 \%$. This is therefore assigned as relative standard error to all diols in Table 5 with label "b".

For 1,7-heptane diol, we have two data sources: Knauth and Sabbah (1990a) and Piacente et al. (1993). Comparing room-temperature data of six diols from Knauth and Sabbah on the one hand (Knauth and Sabbah, 1990b, c) and from Verevkin and co-workers on the other hand (Verevkin, 2007, 2004; Verevkin et al., 2009; Toktonov, 2009), we obtain again a RMSRD of $25 \%$ and assign this as the relative standard error to $p_{\mathrm{L}}^{0}$. The data of Piacente et al. (1993) could not be directly compared with those of Verevkin and coworkers because the two groups did not measure the same diols. We assign the same relative standard error of $25 \%$ to their $p_{\mathrm{L}}^{0}$ data due to lack of alternative. 


\section{A2 Infinite dilution activity coefficient}

The infinite dilution activity coefficient is calculated from $a_{\mathrm{w}}$ data using Eq. (14). If these data were sufficiently finegrained, precise and cover the entire $x_{\mathrm{w}}$ range from 0 to $1, \mathrm{a}$ numerical integration of the integral in Eq. (14) would be appropriate. However, if this is not the case, it might be better to fit the $a_{\mathrm{w}}$ data with a reasonable model. The following models for $\ln \gamma_{\mathrm{w}}$ were considered in this work: Margules, Van Laar, Wilson and UNIQUAC (Carlson and Colburn, 1942; Prausnitz et al., 1999), as they were derived from physical considerations. These models are reproduced below:

$$
\begin{aligned}
& \text { Margules: } f\left(x_{1}, A_{12}, A_{21}\right) \\
& =\left(A_{12}+2\left(A_{21}-A_{12}\right) x_{1}\right) x_{2}^{2} \\
& \text { Van Laar: } f\left(x_{1}, A_{12}, A_{21}\right)=A_{12}\left(\frac{A_{21} x_{2}}{A_{12} x_{1}+A_{21} x_{2}}\right)^{2} \\
& \text { Wilson: } f\left(x_{1}, A_{12}, A_{21}\right)=-\ln \left(x_{1}+A_{12} x_{2}\right) \\
& +x_{2}\left(\frac{A_{12}}{x_{1}+A_{12} x_{2}}-\frac{A_{21}}{A_{21} x_{1}+x_{2}}\right) \\
& \text { UNIQUAC: } f\left(x_{1}, A_{12}, A_{21}\right)=\ln \frac{\Phi_{1}}{x_{1}}+\frac{z}{2} q_{1} \ln \frac{\theta_{1}}{\Phi_{1}} \\
& +\Phi_{2}\left(l_{1}-\frac{r_{1}}{r_{2}} l_{2}\right) \\
& -q_{1}\left[\ln \left(\theta_{1}+\theta_{2} e^{-A_{21} / T}\right)+\theta_{2}\left(\frac{e^{-A_{21} / T}}{\theta}\right.\right. \\
& \left.\left.+\theta_{2} e^{-A_{21} / T}-\frac{e^{-A_{12} / T}}{\theta_{2}+\theta_{1} e^{-A_{12} / T}}\right)\right]
\end{aligned}
$$

with $x_{1}$ the mole fraction of the first component (here water), $x_{2}=1-x_{1}$ the mole fraction of the second component (here the solute), and $A_{12}, A_{21}$ the parameters to fit. To determine $A_{12}, A_{21}$, a least square regression was performed, minimizing the difference between experimental and modelled $\ln \gamma_{w}$. For a detailed overview of the quantities used in the UNIQUAC equation, see Prausnitz et al. (1999). Errors in $\gamma_{\mathrm{s}}^{\infty}$ arise from uncertainty and sparsity in the $a_{\mathrm{w}}$ data, but also from a suboptimal model choice. This is especially important if no data in the highly dilute concentration range are available.

All the $\gamma_{\mathrm{s}}^{\infty}$ derived in this work are based - partially or totally - on the $a_{\mathrm{w}}$ from Marcolli and Peter (2005). This work presents $a_{\mathrm{w}}$ data, relatively coarse-grained, with a $x_{\mathrm{w}}$ range typically between 0.1 and 0.95 . The main limitation of this data source is that no data in the highly dilute range are available. We present here first an error analysis for all the 14 diols from Table 2, but using the data of Marcolli and Peter (2005) only. The four activity coefficient expressions were all tested, and the one that fitted the data best was chosen. The results are presented in Table 6.

Marcolli and Peter (2005) report that the $a_{\mathrm{w}}$ data are "accurate within \pm 0.015 ", as specified by the employed instrument, but this does not make clear whether the error is ran- dom and/or systematic, or whether this range corresponds to e.g. one or two standard deviations. If we assume that the selected fitting model is correct and any systematic error in $a_{\mathrm{W}}$ is absorbed in the fitting parameters, then any remaining deviation between modelled and experimental values should be due to the random error in the experiment (Bevington, 2003). Standard deviations between modelled and observed $a_{\mathrm{w}}$ vary between 0.003 and 0.009 (Table 6). We drew repeatedly random errors from a normal distribution with a standard deviation of 0.0075 (corresponding to $2 \sigma=0.015$ ), using the python scipy.stats module (Jones et al., 2001) and applied these to the $a_{\mathrm{w}}$ data. This resulted in a distribution of $\gamma_{\mathrm{s}}^{\infty}$ values. A relative standard error between $2 \%$ and $14 \%$ on $\gamma_{\mathrm{s}}^{\infty}$ is obtained in this way. We note however, that this error depends also on the selected model, i.e. $\gamma_{\mathrm{s}}^{\infty}$ based on Margules models tend to be the least sensitive to the random shifts, while $\gamma_{\mathrm{s}}^{\infty}$ based on Van Laar and Wilson models are the most sensitive.

Systematic errors in $a_{\mathrm{w}}$ can be estimated by comparing with other data sources (Romero and Páez, 2006; Borghesani et al., 1989). The $a_{\mathrm{w}}$ data of Marcolli and Peter (2005) are typically higher than from the other data sources, with a MD of 0.005 . We applied systematic shifts of \pm 0.005 on the $a_{\mathrm{w}}$ data of Marcolli and Peter (2005). This had a minor impact on $\gamma_{\mathrm{s}}^{\infty}$, between 2 and $6 \%$.

We note that we had expected that the largest $\gamma_{\mathrm{s}}^{\infty}$ (from 1,7-heptane diol and 1,2-hexane diol) would exhibit the largest sensitivity on these random and systematic shifts. This turned out not to be true, however.

Errors due to a suboptimal model choice are more difficult to quantify. Per compound, the other three activity coefficient models (apart from the "best" one) were also considered. If the fitting was considerably worse, the model was rejected because it was probably not appropriate. If the fitting gave essentially the same $\gamma_{\mathrm{s}}^{\infty}$ result, it was also not retained, because in that particular case the models were not truly different. In this way, for seven diols $\gamma_{\mathrm{s}}^{\infty}$ from an alternative model were selected (presented in Table 6). The RMSRD between $\gamma_{\mathrm{s}}^{\infty}$ of the "best" model and "alternative" model was $12 \%$. The most important reason for the discrepancy between the activity coefficient models was their behaviour at the highly dilute region, where no data were used to constrain them.

For eight diols in Table 2, also data from two other sources (Borghesani et al., 1989; Romero and Páez, 2006) were available. Note that Borghesani et al. (1989) do not provide the data points but only fitted expressions. These two data sources are very precise; e.g. Romero and Páez (2006) report a relative uncertainty in $a_{\mathrm{w}}$ of $0.005 \%$ or less. They are also in good agreement with each other; the difference in $a_{\mathrm{w}}$ is typically 0.001 or less. These data cover the highly dilute region ( $x_{\mathrm{w}}$ typically in the range between 0.93 and 0.996 ) and therefore enable us to largely correct for the error due to a suboptimal model choice. Using these data as well, more accurate estimations of $\gamma_{s}^{\infty}$ were made (Table 2). Comparing those with the $\gamma_{\mathrm{s}}^{\infty}$ derived only from the Marcolli and 
Peter (2005) data, a RMSRD of $13 \%$ was obtained, in good agreement with our above estimate of the error due to a suboptimal model choice. Therefore, we assign to all $\gamma_{\mathrm{s}}^{\infty}$ where only data from Marcolli and Peter (2005) are used, a standard error of $13 \%$.

Practically, the derivation of $\gamma_{\mathrm{s}}^{\infty}$ when multiple data sources are available was done in the following way. The integral in Eq. (14) was split into two parts:

$\ln \gamma_{\mathrm{s}}^{\infty}=\int_{t=0}^{\widetilde{x}_{\mathrm{W}}} \frac{\ln \gamma_{\mathrm{w}}\left(x_{\mathrm{w}}\right)}{\left(1-x_{\mathrm{W}}\right)^{2}} \mathrm{~d} x_{\mathrm{w}}+\int_{t=\widetilde{x}_{\mathrm{W}}}^{1} \frac{\ln \gamma_{\mathrm{w}}\left(x_{\mathrm{w}}\right)}{\left(1-x_{\mathrm{W}}\right)^{2}} \mathrm{~d} x_{\mathrm{w}}$

where $\widetilde{x}_{\mathrm{w}}$ marks the start of the highly dilute region for which data of Borghesani et al. (1989) and Romero and Páez (2006) are available. For the region $\left[0, \widetilde{x}_{\mathrm{w}}\right]$ we employed for $\ln \gamma_{\mathrm{w}}$ the corresponding activity coefficient expression from Table 6. For the region $\left[\widetilde{x}_{\mathrm{w}}, 1\right]$, the data from Borghesani et al. (1989) and Romero and Páez (2006) were integrated. This was attained either by a numeric integration, or by fitting an activity coefficient expression over this small region, or - if only data of Borghesani et al. (1989) were available - the analytic expression given in this study was used. We assign to these more accurate estimations of $\gamma_{\mathrm{s}}^{\infty}$ a small standard error of $5 \%$.

For the two triols in Table 2, the data of Marcolli and Peter (2005) and of Ninni et al. (2000) and Scatchard et al. (1938) were combined. There is a good agreement between the data; e.g. Ninni et al. (2000) report that for glycerol, there is only $0.1 \%$ relative deviation between their $a_{\mathrm{w}}$ data and those of Scatchard et al. (1938). Also here we assign a small standard error of $5 \%$ on $\gamma_{\mathrm{s}}^{\infty}$.

\section{A3 Solubility}

As some solubility data of the polyols are from literature compilations, uncertainties are not always available. But when reported, they are typically very low. For xylitol, Wang et al. (2013) reported an error of no more than $0.5 \%$ on $x_{\mathrm{s}}^{\text {sat }}$. For pentaerythritol, a $0.3 \%$ error can be derived from the study of Cheon et al. (2005) and $0.15 \%$ from the study of Chianese et al. (1995). Higher errors are found when comparing different studies. For erythritol, Hao et al. (2005) report a $4 \%$ uncertainty by comparing with literature data. For pentaerythritol, we found by comparing data of Cheon et al. (2005), Chianese et al. (1995) and Mullin (2001) that the RMSRD on room temperature $x_{\mathrm{s}}^{\text {sat }}$ is $5 \%$. Compared to the estimated errors on solid state pressure (see Sect. A5), these errors are very minor. We assign a standard error of $5 \%$ to all solubility values, except for those of 1,9-nonane diol and 1,10-decane diol. For these latter two compounds, there are two issues. First, the data are from a secondary reference (Merck Millipore; http://www.merckmillipore.com/) from which it is difficult to assess the reliability. Second, the solubility is not reported at the reference temperature of
$298.15 \mathrm{~K}$ but at $293.15 \mathrm{~K}$ instead. The temperature dependence of solubility can be described by a van 't Hoff relation (Atkins and de Paula, 2006):

$\frac{d \ln x_{\mathrm{s}}^{\mathrm{sat}}}{d(1 / T)}=-\frac{\Delta H_{\mathrm{Cr} \rightarrow \mathrm{aq}}^{\mathrm{vH}}}{R}$.

The $\Delta H_{\mathrm{Cr} \rightarrow \mathrm{aq}}^{\mathrm{vH}}$ is not known for these two diols. For monoalcohols it can be either positive or negative and is (in absolute value) in the range $0-30 \mathrm{~kJ} \mathrm{~mol}^{-1}$ (based on data from Mackay et al., 2006). Based on this, we estimate roughly the standard error on $x_{\mathrm{s}}^{\text {sat }}$ at $298.15 \mathrm{~K}$ as $15 \%$.

\section{A4 Activity coefficient ratio}

The activity coefficient ratio $\gamma_{\mathrm{s}}^{\infty} / \gamma_{\mathrm{s}}^{\text {sat }}$ is calculated from $a_{\mathrm{w}}$ data. The error on $\gamma_{\mathrm{s}}^{\infty} / \gamma_{\mathrm{s}}^{\text {sat }}$ depends on the solubility. If the solubility is very low, $\gamma_{\mathrm{s}}^{\infty} / \gamma_{\mathrm{s}}^{\text {sat }}$ will necessarily be very close to unity and the uncertainty on $\gamma_{\mathrm{s}}^{\infty} / \gamma_{\mathrm{s}}^{\text {sat }}$ will vanish (see Eq. 18). For all compounds with $x_{\mathrm{s}}^{\text {sat }}<0.1$ we neglect the error. Xylitol, adonitol, arabinitol and sorbitol have relatively high solubilities $\left(x_{\mathrm{s}}^{\mathrm{sat}} \approx 0.2\right)$ and $\gamma_{\mathrm{s}}^{\infty} / \gamma_{\mathrm{s}}^{\text {sat }}$ considerably deviating from 1 (Table 4). For xylitol and sorbitol, precise $a_{\mathrm{w}}$ data are available (Ninni et al., 2000; Comesaña et al., 2001; Bower and Robinson, 1963); e.g. Ninni et al. (2000) report a reproducibility of $\pm 0.001 a_{\mathrm{w}}$ units. There is a good agreement between the data sources. For sorbitol, there is a near perfect agreement between the data sets of Comesaña et al. (2001) and Bower and Robinson (1963) (no significant MD, and a RMSD of 0.0005). The RMSD between the $a_{\mathrm{w}}$ data of Ninni et al. (2000) on the one hand, and the data of Comesaña et al. (2001) and Bower and Robinson (1963) on the other hand, for both xylitol and sorbitol, is 0.003 . This is similar to the standard deviation between modelled $a_{\mathrm{w}}$ and experimental $a_{\mathrm{w}}$ ( 0.0015 for sorbitol, 0.003 for xylitol). Therefore, we applied random shifts from a normal distribution with a standard deviation of 0.003 to the $a_{\mathrm{w}}$ data. This resulted in a $5 \%$ uncertainty on $\gamma_{\mathrm{s}}^{\infty} / \gamma_{\mathrm{s}}^{\text {sat }}$ for sorbitol and a $2.5 \%$ uncertainty for xylitol. We adopted $5 \%$ as a relative standard error for the $\gamma_{\mathrm{s}}^{\infty} / \gamma_{\mathrm{s}}^{\text {sat }}$ of xylitol and sorbitol (Table 8).

Chirife et al. (1984) presented one-parameter fittings of the form $\ln \gamma_{\mathrm{w}}=\exp \left(-A x_{\mathrm{s}}\right)$, from which $\gamma^{\infty} / \gamma^{\text {sat }}$ can be derived. Using Eq. (18), one has

$\ln \frac{\gamma_{\mathrm{s}}^{\infty}}{\gamma_{\mathrm{s}}^{\mathrm{sat}}}=-A x_{\mathrm{s}}^{\mathrm{sat}}\left(2-x_{\mathrm{s}}^{\mathrm{sat}}\right)$.

For adonitol and arabinitol, these are the only data available. $\gamma_{\mathrm{s}}^{\infty} / \gamma_{\mathrm{s}}^{\text {sat }}$ values derived in this way are likely more uncertain than the values given above for sorbitol and xylitol. For these two compounds, we compared our own $\gamma_{\mathrm{s}}^{\infty} / \gamma_{\mathrm{s}}^{\text {sat }}$ values (in Table 4) with the values obtained using the one-parameter fittings of Chirife et al. (1984) and found a RMSRD of $16 \%$. Therefore, we assign a relative standard error of $16 \%$ to the $\gamma_{\mathrm{s}}^{\infty} / \gamma_{\mathrm{s}}^{\text {sat }}$ of adonitol and arabinitol (Table 8). 


\section{A5 Derivation of sublimation data}

Starting from high-temperature solid state pressure data, and heat capacity data, the solid state pressure $p_{\mathrm{Cr}}^{0}$ at $T_{\text {ref }}=$ $298.15 \mathrm{~K}$ is given by

$$
\begin{aligned}
& \ln p_{\mathrm{Cr}}^{0}\left(T_{\text {ref }}\right)=A+B, \text { with } \\
& A=\ln p_{\mathrm{Cr}}^{0}\left(T_{\text {meas }}\right)-\frac{1}{R}\left(\frac{1}{T_{\text {ref }}}-\frac{1}{T_{\text {meas }}}\right) \\
& \Delta H_{\text {sub }}\left(T_{\text {meas }}\right) \\
& B=\frac{1}{R} \int_{T_{\text {meas }}}^{T_{\text {ref }}}\left(C_{p, \mathrm{~g}}-C_{p, \mathrm{Cr}}\right)\left(\frac{1}{T}-\frac{1}{T_{\text {ref }}}\right) \mathrm{d} T .
\end{aligned}
$$

In the case that the high-temperature data corresponds to liquid vapour pressure $p_{\mathrm{L}}^{0}$, the relation is

$$
\begin{aligned}
& \ln p_{\mathrm{Cr}}^{0}\left(T_{\text {ref }}\right)=A+B+C, \text { with } \\
& A=\ln p_{\mathrm{L}}^{0}\left(T_{\text {meas }}\right)-\frac{1}{R}\left(\frac{1}{T_{\text {ref }}}-\frac{1}{T_{\text {meas }}}\right) \\
& \Delta H_{\text {vap }}\left(T_{\text {meas }}\right) \\
& B=\frac{1}{R} \int_{T_{\text {meas }}}^{T_{\text {fus }}}\left(C_{p, \mathrm{~g}}-C_{p, \mathrm{~L}}\right)\left(\frac{1}{T}-\frac{1}{T_{\text {ref }}}\right) \mathrm{d} T \\
& +\frac{1}{R} \int_{T_{\text {fus }}}^{T_{\text {ref }}}\left(C_{p, \mathrm{~g}}-C_{p, \mathrm{Cr}}\right)\left(\frac{1}{T}-\frac{1}{T_{\text {ref }}}\right) \mathrm{d} T \\
& C=-\frac{1}{R}\left(\frac{1}{T_{\text {ref }}}-\frac{1}{T_{\text {fus }}}\right) \Delta H_{\text {fus }}\left(T_{\text {fus }}\right) .
\end{aligned}
$$

Uncertainties on terms $A$ (involving high temperature vapour pressure data), $B$ (involving heat capacity data) and, depending on the case, $C$ (involving fusion data) will contribute to the error on $\ln p_{\mathrm{Cr}}^{0}\left(T_{\mathrm{ref}}\right)$ :

$$
\begin{aligned}
\frac{\mathrm{SE}\left[p_{\mathrm{Cr}}^{0}\left(T_{\mathrm{ref}}\right)\right]}{p_{\mathrm{Cr}}^{0}\left(T_{\mathrm{ref}}\right)} & =\mathrm{SE}\left[\ln p_{\mathrm{Cr}}^{0}\left(T_{\mathrm{ref}}\right)\right] \\
& =\sqrt{\mathrm{SE}[A]^{2}+\mathrm{SE}[B]^{2}+\mathrm{SE}[C]^{2}} .
\end{aligned}
$$

In the next sections these three uncertainties are analysed.

\section{A5.1 High-temperature $p_{\mathrm{Cr}}^{0}$ and $p_{\mathrm{L}}^{0}$ data}

To simplify the discussion, in this section, $p^{0}, \Delta S$ and $\Delta H$ stand for either $p_{\mathrm{Cr}}^{0}, \Delta S_{\text {sub }}$ and $\Delta H_{\text {sub }}$ or $p_{\mathrm{L}}^{0}, \Delta S_{\text {vap }}$ and $\Delta H_{\text {vap }}$ respectively, depending on whether the compound is a solid or a liquid at $T_{\text {meas }}$. Term $A$ is then given by

$$
A=\ln p^{0}\left(T_{\text {meas }}\right)-\frac{1}{R}\left(\frac{1}{T_{\text {ref }}}-\frac{1}{T_{\text {meas }}}\right) \Delta H\left(T_{\text {meas }}\right) .
$$

The standard error of $A$, from the error propagation rule (Bevington, 2003) (neglecting the uncertainty in $T_{\text {meas }}$ ), is equal to
$\operatorname{SE}(A)=$

(A22)

$$
\sqrt{\left(\frac{\mathrm{SE}\left[p^{0}\left(T_{\text {meas }}\right)\right]}{p^{0}\left(T_{\text {meas }}\right)}\right)^{2}+\left[\frac{\mathrm{SE}\left[\Delta H\left(T_{\text {meas }}\right)\right]}{R}\left(\frac{1}{T_{\text {ref }}}-\frac{1}{T_{\text {meas }}}\right)\right]^{2}} .
$$

In the study of Knauth and Sabbah (1990a), $p^{0}\left(T_{\text {meas }}\right)$ and $\Delta H\left(T_{\text {meas }}\right)$ are measured separately and at one fixed temperature. In the other studies, however (Nitta et al., 1951; Bradley and Cotson, 1953; Barone et al., 1990; Nitta et al., 1950; Piacente et al., 1993, 1994), $\Delta H$ was derived from a linear regression of $\ln p^{0}$ vs. $1 / T$. Over the relatively small temperature interval, the temperature dependence of $\Delta H$ can be neglected (Clausius-Clapeyron relation, see e.g. Atkins and de Paula, 2006). Eq. () still applies, if $p_{\mathrm{L}}^{0}$ is taken at the centre of the measurement interval (Ramsey and Shafer, 1997). $T_{\text {meas }}$ then corresponds to the centre of the temperature interval (see Table 3) and is presented in Table 8. Most high-temperature $p^{0}$ data are from Piacente and co-workers, covering both diols and polyols with four or more hydroxyl groups (Piacente et al., 1993, 1994; Barone et al., 1990).

As before (see Sect. A1), we estimate $\frac{\mathrm{SE}\left[p^{0}\left(T_{\text {meas }}\right)\right]}{p^{0}\left(T_{\text {meas }}\right)}$ as 0.25 for the data of Knauth and Sabbah (1990a) and Piacente et al. (1993, 1994). By comparing $\Delta H$ data on diols from Knauth and Sabbah (1990a) and Piacente et al. (1994), we find a RMSD of $3.5 \mathrm{~kJ} \mathrm{~mol}^{-1}$, which we adopt as $\operatorname{SE}\left[\Delta H\left(T_{\text {meas }}\right)\right]$ for both data sources. As is often the case when comparing different data sources, this error is higher than the errors reported in the individual studies themselves (typically $1-2 \mathrm{~kJ} \mathrm{~mol}^{-1}$ ). For large differences between $T_{\text {ref }}$ and $T_{\text {meas }}$, $\mathrm{SE}(A)$ is determined mainly by uncertainty in the enthalpy term. This is the case for the polyols with four or more hydroxyl groups. The largest $\operatorname{SE}(A)$, about 0.6 , is obtained for the hexols (Table 8).

Most data on polyols with four or more hydroxyl groups is from Piacente and co-workers (Barone et al., 1990). There are a few other, much older studies (Nitta et al., 1950, 1951; Bradley and Cotson, 1953) on erythritol and pentaerythritol, with $\Delta H$ values strongly deviating $\left(15-30 \mathrm{~kJ} \mathrm{~mol}^{-1}\right.$ lower) from the data of Barone et al. (1990). These large discrepancies cannot be understood from the reported precisions, or from the error of $3.5 \mathrm{~kJ} \mathrm{~mol}^{-1}$ adopted above. We think that this points to problems with one or more of the experimental studies, rather than to a typical experimental uncertainty. We judge the data of Piacente and co-workers as the more reliable, for the following reasons. (i) A relatively good agreement in $\Delta H$ of diols with Knauth and Sabbah (1990a) (Piacente et al., 1993, 1994). (ii) Piacente and co-workers also present $p_{\mathrm{L}}^{0}$ measurements on diols using another technique, and with comparable results (Piacente et al., 1993). (iii) Consistency, in the sense that the high-temperature $p_{\mathrm{L}}^{0}$ data of stereo-isomers of polyols are comparable, as one would expect (Barone et al., 1990). (iv) Compared to the older studies, 
those of Piacente and co-workers employ more data points and a larger temperature interval. Obviously, more $p^{0}$ measurements on polyols with four or more hydroxyl groups are desirable.

\section{A5.2 Heat capacity data}

Assuming that the error on heat capacity is temperature independent, one derives from Eq. () for the standard error on term $B$ (if no fusion point is involved)

$$
\begin{aligned}
& \mathrm{SE}[B]=\frac{1}{R}\left[\ln \frac{T_{\text {ref }}}{T_{\text {meas }}}-\frac{1}{T_{\text {ref }}}\left(T_{\text {ref }}-T_{\text {meas }}\right)\right] \\
& \sqrt{\mathrm{SE}\left[C_{p, \mathrm{~g}}\right]^{2}+\mathrm{SE}\left[C_{p, \mathrm{Cr}}\right]^{2}} .
\end{aligned}
$$

If there is a fusion point, starting from Eq. (A19), the standard error on term $B$ becomes

$$
\begin{aligned}
& \mathrm{SE}[B]=\frac{1}{R}\left[\ln \frac{T_{\text {fus }}}{T_{\text {meas }}}-\frac{1}{T_{\text {ref }}}\left(T_{\text {fus }}-T_{\text {meas }}\right)\right] \\
& \sqrt{\mathrm{SE}\left[C_{p, \mathrm{~g}}\right]^{2}+\mathrm{SE}\left[C_{p, \mathrm{~L}}\right]^{2}}+ \\
& \frac{1}{R}\left[\ln \frac{T_{\text {ref }}}{T_{\text {fus }}}-\frac{1}{T_{\text {ref }}}\left(T_{\text {ref }}-T_{\text {fus }}\right)\right] \\
& \sqrt{\mathrm{SE}\left[C_{p, \mathrm{~g}}\right]^{2}+\mathrm{SE}\left[C_{p, \mathrm{Cr}}\right]^{2}} .
\end{aligned}
$$

Most $C_{p, \mathrm{~L}}$ and $C_{p, \mathrm{Cr}}$ data we use is from Tong and coworkers (Tong et al., 2007, 2008, 2009, 2010b, a), as it covers a wide range of polyols and temperatures. Quoted errors on the experimental values of $C_{p, \mathrm{~L}}$ and $C_{p, \mathrm{Cr}}$ are very low, e.g. $0.2 \%$ for those of Tong and co-workers. This corresponds to about $0.5 \mathrm{~J} /(\mathrm{Kmol})$ error on the heat capacity value. However, the discrepancy between data of different groups is much larger. We compared the data of Tong and co-workers with other data where possible: for erythritol (Lopes Jesus et al., 2005; Spaght et al., 1931), sorbitol (Lian et al., 1982) and mannitol (Lian et al., 1982; Spaght et al., 1931). Based on the RMSD of the data, we assign $\mathrm{SE}\left[C_{p, \mathrm{~L}}\right]=\mathrm{SE}\left[C_{p, \mathrm{Cr}}\right]=20 \mathrm{~J} /(\mathrm{Kmol})$, much larger than the reported errors. By taking identical errors for $C_{p, \mathrm{~L}}$ and $C_{p, \mathrm{Cr}}$ (there are not enough data to treat them separately), Eq. (A24) simplifies to Eq. (A23).

In a few cases (arabinitol, dulcitol, liquid state mannitol) we did not found heat capacity data in the appropriate temperature range and we took heat capacity data of a stereoisomer instead (see Table 3). To test the validity of this assumption, we compared heat capacity data at or above room temperature of stereo-isomers from the same research group. Regarding the liquid state, $C_{p, \mathrm{~L}}$ data of the stereo-isomers erythritol and threitol (Lopes Jesus et al., 2005), and of the stereo-isomers xylitol and adonitol (Tong et al., 2007, 2010b) differ by less than $2 \mathrm{~J} /(\mathrm{Kmol})$. This justifies the approximations $C_{p, \mathrm{~L}}$ (arabinitol) $\approx C_{p, \mathrm{~L}}($ xylitol $), C_{p, \mathrm{~L}}($ dulcitol $) \approx$ $C_{p, \mathrm{~L}}$ (sorbitol) and $C_{p, \mathrm{~L}}$ (mannitol) $\approx C_{p, \mathrm{~L}}$ (sorbitol) applied in this work. Regarding the solid state, we compared
$C_{p, \mathrm{Cr}}$ of stereo-isomers erythritol and threitol (Lopes Jesus et al., 2005), xylitol and adonitol (Tong et al., 2007, 2010b), mannitol and sorbitol (Tong et al., 2010a, 2008; Lian et al., 1982), only taking into account the data at $T \geq T_{\text {ref (as }}$ this is the most relevant for our work) and found a RMSD of $9 \mathrm{~J} /(\mathrm{Kmol})$. This is larger than for the liquid state but still smaller than the discrepancies between different works on the same molecule. Moreover, for the low-temperature (88-291 K) $C_{p, \text { Cr }}$ data for the stereo-isomers dulcitol and mannitol (Parks and Huffman, 1926; Parks and Anderson, 1926), the RMSD was only $2 \mathrm{~J} /(\mathrm{Kmol})$. Therefore, also the approximations $C_{p, \mathrm{Cr}}$ (arabinitol) $\approx C_{p, \mathrm{Cr}}($ xylitol $)$ and $C_{p, \mathrm{Cr}}$ (dulcitol) $\approx C_{p, \mathrm{Cr}}$ (mannitol) seem to be justified.

Regarding $C_{p, \mathrm{~g}}$, the error is difficult to quantify as this value is not measured but obtained by the Benson group contribution method. Poling et al. (2001) quote a relative error of $1 \%$ for this method, but as polyols are under-represented in the fitting set of this method, this is probably not realistic. The method of Domalski and Hearing (1993) is a very close relative to the Benson group contribution method (although limited to room temperature), yielding very similar results for $C_{p, \mathrm{~g}}$. Importantly, this method also estimates $C_{p, \mathrm{~L}}$ and $C_{p, \mathrm{Cr}}$. Comparing $C_{p, \mathrm{Cr}}$ for erythritol, xylitol and sorbitol from Tong and co-workers with estimations by the method of Domalski and Hearing (1993) yields a RMSD of $20 \mathrm{~J} /(\mathrm{Kmol})$. We make now the assumption that this error is applicable to $C_{p, \mathrm{~g}}$ as well. Hence we assign $\mathrm{SE}\left[C_{p, \mathrm{~g}}\right]=$ $20 \mathrm{~J} /(\mathrm{Kmol})$.

For the diols, where $T_{\text {meas }}$ is relatively close to $T_{\text {ref }}, \mathrm{SE}[B]$ is small $(1-7 \%)$, but for the compounds with four or more hydroxyl groups it becomes more important - over $40 \%$ for the hexols (see Table 8).

\section{A5.3 Fusion data}

In this section the error due to the term $C=$ $-\frac{1}{R}\left(\frac{1}{T_{\text {ref }}}-\frac{1}{T_{\text {fus }}}\right) \Delta H_{\text {fus }}\left(T_{\text {fus }}\right)$ in Eq. (A17) is estimated. From the error propagation rule the standard error can be derived as

$\mathrm{SE}[C]=$

$\sqrt{\mathrm{SE}\left[T_{\text {fus }}\right]^{2}\left(\frac{\Delta H_{\text {fus }}}{T_{\text {fus }}^{2} R}\right)^{2}+\mathrm{SE}\left[\Delta H_{\text {fus }}\right]^{2}\left[\frac{1}{R}\left(\frac{1}{T_{\text {ref }}}-\frac{1}{T_{\text {fus }}}\right)\right]^{2}}$.

Fusion data were collected from Tong et al. (2007, 2008, 2009, 2010b, a), Barone et al. (1990), Badea et al. (2014) and Knauth and Sabbah (1990a). The selected $T_{\text {fus }}$ are presented in Table 8. Reported errors in these works are typically $0.1 \mathrm{~K}$ for $T_{\text {fus }}$ and $0.1-0.3 \mathrm{~kJ} \mathrm{~mol}^{-1}$ for $\Delta H_{\text {fus }}$. However, comparing the data between the different references reveals larger uncertainties: a standard deviation of $2.8 \mathrm{~K}$ for $T_{\text {fus }}$ and $2.2 \mathrm{~kJ} \mathrm{~mol}^{-1}$ for $\Delta H_{\text {fus }}$. Using these errors, $\operatorname{SE}(C)$ ranges from 0.13 for nonane diol to 0.33 for dulcitol (see Table 8). 


\section{A6 Overall discussion of errors}

Table 7 gives an overview of the estimated relative standard errors on $p_{\mathrm{L}}^{0}, \gamma_{\mathrm{s}}^{\infty}$ and the derived relative standard error on $k_{h}$. This applies to the compounds which are liquid at room temperature, i.e. most diols discussed in this work and glycerol. The relative standard error on $k_{h}$ ranges between $6 \%$ and $30 \%$.

Table 8 gives the different error contributions when the compound is solid at room temperature, and the resulting relative standard error on $k_{h}$. In all cases, $\operatorname{SE}(A)$ is the dominant error contribution. For all polyols with four or more hydroxyl groups, this is caused by the large difference between $T_{\text {meas }}$ and $T_{\text {ref }}$ and the uncertainty on $\Delta H_{\text {fus }}$. The estimated relative standard error on $k_{h}$ ranges between 30 and $80 \%$.

\section{Appendix B: Alternative method to estimate $p_{\mathrm{Cr}}^{0}\left(T_{\text {ref }}\right)$ data from high-temperature $p_{\mathrm{L}}^{0}$ data}

As is clear from Sect. A, using high-temperature $p^{0}$ data at $T_{\text {meas }}$ far above $T_{\text {ref }}$ contributes the largest uncertainty to the derived room temperature $p_{\mathrm{Cr}}^{0}$ and $k_{h}$ data. One of the reviewers suggested an alternative approach. It can be described as follows:

1. Select a vapour pressure estimation method that uses a boiling point as input (e.g. Nannoolal et al., 2008).

2. Adjust the boiling point such that the experimental hightemperature $p_{\mathrm{L}}^{0}$ data at $T_{\text {meas }}$ are reproduced.

3. With this setting, estimate the subcooled $p_{\mathrm{L}}^{0}$ at $T_{\text {ref. }}$.

4. Use triple point or fusion point data to calculate $p_{\mathrm{Cr}}^{0}$ at $T_{\text {ref }}$ (Prausnitz et al., 1999; Compernolle et al., 2011, Eq. (1)).
We applied this procedure up to step 3. The selected vapour pressure estimation methods are those of Nannoolal et al. (2008), Moller et al. (2008) and Myrdal and Yalkowsky (1997), available at the site E-AIM (http://www.aim.env.uea. ac.uk/aim/aim.php), and applied to the compounds erythritol, xylitol and sorbitol. The boiling point was adjusted until the $p_{\mathrm{L}}^{0}$ data at $T_{\text {meas }}$ of Barone et al. (1990) could be reproduced, and $p_{\mathrm{L}}^{0}$ at $T_{\text {ref }}$ calculated. The results are presented in Table 9 . The method of Myrdal and Yalkowsky (1997) gives much higher $p_{\mathrm{L}}^{0}\left(T_{\text {ref }}\right)$ estimations than the other two methods; for sorbitol it is more than two orders of magnitude higher. The $p_{\mathrm{L}}^{0}\left(T_{\text {ref }}\right)$ estimations using the methods of Nannoolal et al. (2008) and of Moller et al. (2008) are within a factor of 2. However, the adjusted boiling point varies strongly between both methods (almost $100 \mathrm{~K}$ for sorbitol), indicating also problems here.

From the theses describing these two methods (Nannoolal, 2006; Moller, 2007) it can be deduced that to derive these methods, only compounds were selected where also a normal boiling point is available. This excludes the polyols with four or more hydroxyl groups. Therefore, these methods may not be well suited to calculate the vapour pressure of these kind of compounds. In fact, the original version of the method of Moller et al. (2008) contained a bug that we pointed out (Compernolle et al., 2010), showing up only for highly polyfunctional compounds, and giving very unrealistic $p_{\mathrm{L}}^{0}$ values. While this bug has been corrected since then, it does indicate that the method was not devised for highly polyfunctional compounds.

In conclusion, we do not think that this approach is a good alternative to obtain $p_{\mathrm{Cr}}^{0}$ at $T_{\text {ref }}$ 
Acknowledgements. This work was supported by the project BIOSOA (SD/CS/05A, 2011-2014) funded by the Belgian Science Policy Office.

Edited by: D. Topping

\section{References}

Apelblat, A.: Dissociation constants and limiting conductances of organic acids in water, J. Mol. Liq., 95, 99-145, 2002.

Atkins, P. and de Paula, J.: Physical Chemistry, Oxford University Pres, 2006.

Badea, E., Nowicka, B., and Della Gatta, G.: Thermodynamics of fusion and sublimation for a homologous series of eleven alkane$\alpha, \omega$-diols $\mathrm{HO}-\left(\mathrm{CH}_{2}\right)_{\mathrm{n}}$-OH: structure-related odd-even effect, J. Chem. Thermodyn., 68, 90-97, 2014.

Bao, L., Matsumoto, M., Kubota, T., Sekiguchi, K., Wang, Q., and Sakamoto, K.: Gas/particle partitioning of low-molecular-weight dicarboxylic acids at a suburban site in Saitama, Japan, Atmos. Environ., 47, 546-553, 2012.

Barone, G., Gatta, G. D., Ferro, D., and Piacente, V.: Enthalpies and entropies of sublimation, vaporization and fusion of nine polyhydric alcohols, J. Chem. Soc. Faraday T., 86, 75-79, 1990.

Bastos, M., Nilsson, S.-O., Ribeiro da Silva, M. D., Ribeiro da Silva, M. A., and Wadsö, I.: Thermodynamic properties of glycerol enthalpies of combustion and vaporization and the heat capacity at $298.15 \mathrm{~K}$. Enthalpies of solution in water at 288.15 , 298.15, and 308.15 K, J. Chem. Thermodyn., 20, 1353-1359, 1988.

Benson, S. W.: Thermochemical Kinetics: Methods for the Estimation of Thermochemical Data and Rate Parameters, John Wiley \& Sons, New York, 1976.

Bevington, P. R.: Data reduction and error analysis for the physical sciences, New York: McGraw-Hill, third edn., 2003.

Bone, R., Cullis, P., and Wolfenden, R.: Solvent effects on equilibria of addition of nucleophiles to acetaldehyde and the hydrophilic character of diols, J. Am. Chem. Soc., 105, 1339-1343, doi:10.1021/ja00343a044, 1983.

Bonner, O. D. and Breazeale, W. H.: Osmotic and activity coefficients of some nonelectrolytes, J. Chem. Eng. Data, 10, 325-327, doi:10.1021/je60027a007, 1965.

Borghesani, G., Pedriali, R., and Pulidori, F.: Solute-solute-solvent interactions in dilute aqueous solutions of aliphatic diols. Excess enthalpies and gibbs free energies, J. Solution Chem., 18, 289300, 1989.

Bower, V. E. and Robinson, R. A.: Isopiestic vapor pressure measurements of the ternary system: sorbitol-sodium chloride-water at $25^{\circ} \mathrm{C}$, J. Phys. Chem., 67, 1540-1541, doi:10.1021/j100801a033, 1963.

Bradley, R. S. and Cotson, S.: The vapour pressure and lattice energy of hydrogen-bonded crystals, Part II. $\alpha$ - and $\beta$-anhydrous oxalic acid and tetragonal pentaerythritol, J. Chem. Soc., 16841688, doi:10.1039/JR9530001684, 1953.

Brocos, P., Piñeiro, Á., Amigo, A., and Gracia-Fadrique, J.: A proposal for the estimation of binary mixture activity coefficients from surface tension measurements throughout the entire concentration range, Fluid Phase Equilibr., 260, 343-353, 2007.
Cammenga, H. K., Schulze, F. W., and Theuerl, W.: Vapor pressure and evaporation coefficient of glycerol, J. Chem. Eng. Data, 22, 131-134, 1977.

Carlson, H. C. and Colburn, A. P.: Vapor-liquid equilibria of nonideal solutions, Ind. Eng. Chem., 34, 581-589, doi:10.1021/ie50389a013, 1942.

Cheon, Y.-H., Kim, K.-J., and Kim, S.-H.: A study on crystallization kinetics of pentaerythritol in a batch cooling crystallizer, Chem. Eng. Sci., 60, 4791-4802, doi:10.1016/j.ces.2005.03.035, 2005.

Chianese, A., Karel, M., and Mazzarotta, B.: Nucleation kinetics of pentaerythritol, Chem. Eng. J. Bioch. Eng., 58, 209-214, doi:10.1016/0923-0467(94)02896-6, 1995.

Chirife, J., Favetto, G., and Fontán, C. F.: Microbial growth at reduced water activities: some physicochemical properties of compatible solutes, J. Appl. Bacteriol., 56, 259-268, doi:10.1111/j.1365-2672.1984.tb01346.x, 1984.

Claeys, M., Graham, B., Vas, G., Wang, W., Vermeylen, R., Pashynska, V., Cafmeyer, J., Guyon, P., Andreae, M. O., Artaxo, P., and Maenhaut, W.: Formation of secondary organic aerosols through photooxidation of isoprene, Science, 303, 1173-1176, doi:10.1126/science.1092805, 2004.

Clegg, S. L. and Seinfeld, J. H.: Thermodynamic models of aqueous solutions containing inorganic electrolytes and dicarboxylic acids at 298.15 K. 2. Systems including dissociation equilibria, J. Phys. Chem. A, 110, 5718-5734, doi:10.1021/jp056150j, 2006.

Cohen, S., Marcus, Y., Migron, Y., Dikstein, S., and Shafran, A.: Water sorption, binding and solubility of polyols, J. Chem. Soc. Faraday T., 89, 3271, doi:10.1039/ft9938903271, 1993.

Comesaña, J. F., Correa, A., and Sereno, A. M.: Water activity in sorbitol or xylitol + water and sorbitol or xylitol + sodium chloride + water systems at $20^{\circ} \mathrm{C}$ and $35^{\circ} \mathrm{C}$, J. Chem. Eng. Data, 46, 716-719, doi:10.1021/je0003187, 2001.

Compernolle, S., Ceulemans, K., and Müller, J.-F.: Influence of non-ideality on condensation to aerosol, Atmos. Chem. Phys., 9, 1325-1337, doi:10.5194/acp-9-1325-2009, 2009.

Compernolle, S., Ceulemans, K., and Müller, J.-F.: Technical Note: Vapor pressure estimation methods applied to secondary organic aerosol constituents from $\alpha$-pinene oxidation: an intercomparison study, Atmos. Chem. Phys., 10, 6271-6282, doi:10.5194/acp-10-6271-2010, 2010.

Compernolle, S., Ceulemans, K., and Müller, J.-F.: EVAPORATION: a new vapour pressure estimation method for organic molecules including non-additivity and intramolecular interactions, Atmos. Chem. Phys., 11, 9431-9450, doi:10.5194/acp-119431-2011, 2011.

Compernolle, S. and Müller, J.-F.: Henry's law constants of diacids and hydroxy polyacids: recommended values, Atmos. Chem. Phys., 14, 2699-2712, doi:10.5194/acp-14-2699-2014, 2014.

Della Gatta, G., Jóźwiak, M., and Ferloni, P.: Heat capacities near room temperature of ten solid alkane- $\alpha, \omega$-diols $\mathrm{HO}-\left(\mathrm{CH}_{2}\right)_{\mathrm{n}^{-}}$ $\mathrm{OH}$ where $n=6$ and 8-16, J. Chem. Thermodyn., 31, 537-546, 1999.

Domalski, E. S. and Hearing, E. D.: Estimation of the Thermodynamic Properties of C-H-N-O-S-Halogen Compounds at 298.15 K, J. Phys. Chem. Ref. Data, 22, 805-1159, 1993.

Engineering Sciences Data Unit Ltd: Vapour Pressures and Critical Points of Liquids. Glycols and Cyclic Diols, Item No 95002, vol. 2d(ii), ESDU International, London, 1995. 
Ervens, B., Turpin, B. J., and Weber, R. J.: Secondary organic aerosol formation in cloud droplets and aqueous particles (aqSOA): a review of laboratory, field and model studies, Atmos. Chem. Phys., 11, 11069-11102, doi:10.5194/acp-1111069-2011, 2011.

Fredenslund, A., Jones, R. L., and Prausnitz, J. M.: GroupContribution Estimation Of Activity-Coefficients In Nonideal Liquid-Mixtures, AIChE J., 21, 1086-1099, 1975.

Friese, E. and Ebel, A.: Temperature dependent thermodynamic model of the system $\mathrm{H}^{+}-\mathrm{NH}_{4}^{+}-\mathrm{Na}^{+}-\mathrm{SO}_{4}^{2-}-\mathrm{NO}_{3}^{-}-\mathrm{Cl}^{-}-\mathrm{H}_{2} \mathrm{O}$, J. Phys. Chem. A, 114, 11595-11631, doi:10.1021/jp101041j, 2010.

Góralski, P. and Tkaczyk, M.: Heat capacities of some liquid $\alpha, \omega$-Alkanediols within the Temperature Range between (293.15 and 353.15) K, J. Chem. Eng. Data, 53, 1932-1934, doi:10.1021/je800356x, 2008.

Gracia-Fadrique, J., Brocos, P., Piñeiro, A., and Amigo, A.: Activity coefficients at infinite dilution from surface tension data, Langmuir, 18, 3604-3608, doi:10.1021/la011761y, 2002.

Hao, H.-X., Hou, B.-H., Wang, J.-K., and Zhang, M.-J.: Solubility of erythritol in different solvents, J. Chem. Eng. Data, 50, 14541456, doi:10.1021/je0501033, 2005.

Jasra, R. and Ahluwalia, J.: Enthalpies of solution, partial molal heat capacities and apparent molal volumes of sugars and polyols in water, J. Solution Chem., 11, 325-338, doi:10.1007/2BF00649291, 1982.

Joback, K. and Reid, R.: Estimation of pure-component properties from group-contributions, Chem. Eng. Commun., 57, 233-243, 1987.

Jones, E., Oliphant, T., Peterson, P., et al.: SciPy: Open source scientific tools for Python, http://www.scipy.org/ (last access: October 2014), 2001.

Knauth, P. and Sabbah, R.: Energetics of intra- and intermolecular bonds in o-alkanediols. III. Thermochemical study of 1,6hexanediol, 1,7-heptanediol, 1,8-octanediol, 1,9-nonanediol, and 1,10-decanediol at 298.15 K, Can. J. Chem., 68, 731-734, 1990a.

Knauth, P. and Sabbah, R.: Energetics of inter. and intramolecular bonds in alkanediols. IV. the thermochemical study of 1,2alkanediols at $298.15 \mathrm{~K}$, Thermochim. Acta, 164, 145-152, 1990b.

Knauth, P. and Sabbah, R.: Energetics of intra- and intermolecular bonds in $\omega$-alkanediols, Struct. Chem., 1, 43-46, doi:10.1007/BF00675783, 1990c.

Kulikov, D., Verevkin, S. P., and Heintz, A.: Enthalpies of vaporization of a series of aliphatic alcohols: Experimental results and values predicted by the ERAS-model, Fluid Phase Equilib., 192, 187-207, 2001.

Lian, Y.-N., Chen, A.-T., Suurkuusk, J., Wadsö, I., Sokolov, V. B., Spiridonov, V. P., and Strand, T. G.: Polyol-Water Interactions as Reflected by Aqueous Heat Capacity Values., Acta Chem. Scand., 36a, 735-739, doi:10.3891/acta.chem.scand.36a-0735, 1982.

Lopes Jesus, A., Ermelinda Eusébio, M., Redinha, J., and Leitão, M.: Enthalpy of solvation of butanediols in different solvents, Thermochim. Ac., 344, 3-8, 2000.

Lopes Jesus, A. J., Tomé, L. I. N., Eusébio, M. E., and Redinha, J. S.: Enthalpy of Sublimation in the Study of the Solid State of Organic Compounds. Application to Erythritol and Threitol, J. Phys. Chem. B, 109, 18 055-18 060, 2005.
Mackay, D., Shiu, W. Y., Ma, K.-C., and Lee, S. C.: Handbook of Physical-Chemical Properties and Environmental Fate for Organic Chemicals, CRC Press, 2006.

Mansoori, G. A.: Classical thermodynamic basis of activity coefficients: predictive and consistency rules for binary and ternary mixtures based on the relation between excess Gibbs free energies of (c)- and (c-1)-component mixtures, Fluid Phase Equilib. 4, 197-209, 1980.

Marcolli, C. and Peter, Th.: Water activity in polyol/water systems: new UNIFAC parameterization, Atmos. Chem. Phys., 5, 15451555, doi:10.5194/acp-5-1545-2005, 2005.

Martin, S. T.: Phase transitions of aqueous atmospheric particles, Chem. Rev., 100, 3403-3454, 2000.

Matsumoto, Y., Touhara, H., Nakanishi, K., and Watanabe, N.: Molar excess enthalpies for water + ethanediol, + 1,2-propanediol, and $+1,3$-propanediol at $298.15 \mathrm{~K}$, J. Chem. Thermodyn., 9, 801-805, 1977.

Moller, B.: Development of an Improved Group Contribution Method for the Prediction of Vapour Pressures of Organic Compounds, Ph.D. thesis, University of KwaZulu-Natal Durban, 2007.

Moller, B., Rarey, J., and Ramjugernath, D.: Estimation of the vapour pressure of non-electrolyte organic compounds via group contributions and group interactions, J. Mol. Liq., 143, 52-63, 2008.

Mullin, J. W.: Crystallization, 4th edn., Butterworth-Heinemann, Linacre House, Jordan Hill, Oxford OX2 8DP, 2001.

Myrdal, P. B. and Yalkowsky, S. H.: Estimating Pure Component Vapor Pressures of Complex Organic Molecules, Ind. Eng. Chem. Res., 36, 2494-2499, doi:10.1021/ie9502421, 1997.

Nannoolal, Y.: Development and Critical Evaluation of Group Contribution Methods for the Estimation of Critical Properties, Liquid Vapour Pressure and Liquid Viscosity of Organic Compounds, Ph.D. thesis, University of Kwazulu-Natal, Durban Campus, 2006.

Nannoolal, Y., Rarey, J., and Ramjugernath, D.: Estimation of pure component properties: Part 3. Estimation of the vapor pressure of non-electrolyte organic compounds via group contributions and group interactions, Fluid Phase Equilibr., 269, 117-133, doi:10.1016/j.fluid.2006.11.014, 2008.

Nichols, N., Sköld, R., Spink, C., and Wadsö, I.: Thermochemistry of solutions of biochemical model compounds 6. $\alpha, \omega$ dicarboxylic acids, -diamines, and -diols in aqueous solution, J. Chem. Thermodyn., 8, 993-999, 1976.

Ninni, L., Camargo, M. S., and Meirelles, A. J. A.: Water activity in polyol systems, J. Chem. Eng. Data, 45, 654-660, doi:10.1021/je990303c, 2000.

Nitta, I., Seki, S., Momotani, M., Suzuki, K., and Nakagawa, S.: On the phase transition in pentaerythritol (II), P. Jpn Acad., 26 , 11-18, 1950.

Nitta, I., Seki, S., and Suzuki, K.: Energy of hydrogen bond in tetragonal pentaerythritol, B. Chem. Soc. Jpn., 24, 63-69, 1951.

Nordström, F. L. and Rasmuson, A. C.: Determination of the activity of a molecular solute in saturated solution, J. Chem. Thermodyn., 40, 1684-1692, doi:http://dx.doi.org/10.1016/j.jct.2008.06.016, 2008.

Páez, M. S., Alvis, A., and Arrazola, G.: Comportamiento superficial e interfacial de soluciones acuosas diluidas de 
isómeros de pentanodiol a $288.15 \mathrm{~K}$, Inf. Tecnol., 22, 65-70, doi:10.4067/s0718-07642011000100009, 2011.

Pankow, J. F. and Asher, W. E.: SIMPOL.1: a simple group contribution method for predicting vapor pressures and enthalpies of vaporization of multifunctional organic compounds, Atmos. Chem. Phys., 8, 2773-2796, doi:10.5194/acp-8-27732008, 2008.

Paraskevas, P. D., Sabbe, M. K., Reyniers, M.-F., Papayannakos, N., and Marin, G. B.: Group additive values for the gas-phase standard enthalpy of formation, entropy and heat capacity of oxygenates, Chem. Eur. J., 19, 16431-16452, doi:10.1002/chem.201301381, 2013.

Parks, G. S. and Anderson, C. T.: Thermal data on organic compounds. III. The heat capacities, entropies and free energies of tertiary butyl alcohol, mannitol, erythritol and normal butyric acid, J. Am. Chem. Soc., 48, 1506-1512, doi:10.1021/ja01417a009, 1926.

Parks, G. S. and Huffman, H. M.: Thermal data on organic compounds. IV. The heat capacities, entropies and free energies of normal propyl alcohol, ethyl ether and dulcitol, J. Am. Chem. Soc., 48, 2788-2793, doi:10.1021/ja01690a004, 1926.

Peng, C., Chan, M. N., and Chan, C. K.: The hygroscopic properties of dicarboxylic and multifunctional acids: measurements and UNIFAC predictions, Environ. Sci. Technol., 35, 4495-4501, 2001.

Piacente, V., Ferro, D., and Della Gatta, G.: Vaporization enthalpies of a series of $\alpha, \omega$-alkanediols from vapour pressure measurements, Thermochim. Ac., 223, 65-73, 1993.

Piacente, V., Ferro, D., and Della Gatta, G.: Vaporization enthalpies of five odd-numbered (C7 to $\mathrm{C} 15) \alpha, \omega$-alkanediols, Thermochim. Ac., 232, 317-321, 1994.

Poling, B. E., Prausnitz, J. M., and O'Connell, J. P.: The properties of gases and liquids, McGraw-Hill, New York, USA, 5 edn., 2001.

Prausnitz, J. M., Lichtenthaler, R. N., and de Azevedo, E. G.: Molecular Thermodynamics of Fluid-Phase Equilibria, 3rd edn., Prentice-Hall PTR, Upper Saddle River, New Jersey 07458, 1999.

Ramsey, F. L. and Shafer, D. W.: The Statistical Sleuth: A Course in Methods of Data Analysis, Duxbury Press, 1997.

Robinson, R. A. and Stokes, R. H.: Activity coefficients in aqueous solutions of sucrose, mannitol and their mixtures at $25^{\circ} \mathrm{C}$, J. Phys. Chem., 65, 1954-1958, doi:10.1021/j100828a010, 1961.

Romero, C. M. and Páez, M. S.: Isopiestic determination of osmotic and activity coefficients of aqueous solutions of aliphatic polyols at 298.15 K, Fluid Phase Equilibr., 240, 140-143, 2006.

Romero, C. M., Páez, M. S., Miranda, J. A., Hernández, D. J., and Oviedo, L. E.: Effect of temperature on the surface tension of diluted aqueous solutions of 1,2-hexanediol, 1,5-hexanediol, 1,6hexanediol and 2,5-hexanediol, Fluid Phase Equilibr., 258, 6772, 2007.

Sabbe, M. K., De Vleeschouwer, F., Reyniers, M.-F., Waroquier, M., and Marin, G. B.: First principles based group additive values for the gas phase standard entropy and heat capacity of hydrocarbons and hydrocarbon radicals, J. Phys. Chem. A, 112, 12235-12251, doi:10.1021/jp807526n, 2008.

Sander, R.: Compilation of Henry's Law Constants for Inorganic and Organic Species of Potential Importance in Environmental
Chemistry (Version 3), Public Report, available at: http://www. henrys-law.org/ (last access: 1 May 2014), 1999.

Saxena, P. and Hildemann, L. M.: Water-soluble organics in atmospheric particles: a critical review of the literature and application of thermodynamics to identify candidate compounds, J. Atmos. Chem., 24, 57-109, 1996.

Scatchard, G., Hamer, W. J., and Wood, S. E.: Isotonic solutions. I. The chemical potential of water in aqueous solutions of sodium chloride, potassium chloride, sulfuric acid, sucrose, urea and glycerol at $25^{\circ} \mathrm{C}$, J. Am. Chem. Soc., 60, 3061-3070, doi:10.1021/ja01279a066, 1938.

Seidell, A.: Solubilities of Organic Compounds, D. Van Nostrand Co., 3rd Edn., 250 Fourth Avenue, New York, 1941.

Spaght, M. E., Thomas, S. B., and Parks, G. S.: Some Heat-Capacity Data on Organic Compounds obtained with a Radiation Calorimeter, J. Phys. Chem., 36, 882-888, doi:10.1021/j150333a009, 1931.

Stein, S. and Brown, R.: NIST Chemistry WebBook, NIST Standard Reference Database Number 69, chap. Structures and Properties Group Additivity Model, National Institute of Standards and Technology, Gaithersburg MD, 20899, available at: http: //webbook.nist.gov, last access: 1 May 2014.

Suleiman, D. and Eckert, C. A.: Limiting activity coefficients of diols in water by a dew point technique, J. Chem. Eng. Data, 39, 692-696, doi:10.1021/je00016a011, 1994.

Suzuki, T., Ohtaguchi, K., and Koide, K.: Application of principal components analysis to calculate Henry's constant from molecular structure, Comput. Chem., 16, 41-52, 1992.

Toktonov, A. V.: Thermochemical insight into "green chemistry" processes: experiment and ab initio calculations, Ph.D. thesis, Rostock University, available at: http://rosdok.uni-rostock.de/ resolve/id/rosdok_disshab_000000000219 (last access: 1 May 2014), 2009.

Tong, B., Tan, Z.-C., Shi, Q., Li, Y.-S., Yue, D.-T., and Wang, S.X.: Thermodynamic investigation of several natural polyols (I): heat capacities and thermodynamic properties of xylitol, Thermochim. Ac., 457, 20-26, doi:10.1016/j.tca.2007.02.022, 2007.

Tong, B., Tan, Z., Shi, Q., Li, Y., and Wang, S.: Thermodynamic investigation of several natural polyols (II), J. Therm. Anal. Calorim., 91, 463-469, doi:10.1007/s10973-007-8361-8, 2008.

Tong, B., Tan, Z., Zhang, J., and Wang, S.: Thermodynamic investigation of several natural polyols, J. Therm. Anal. Calorim., 95, 469-475, doi:10.1007/s10973-008-9268-8, 2009.

Tong, B., Liu, R.-B., Meng, C.-G., Yu, F.-Y., Ji, S.-H., and Tan, Z.C.: Heat capacities and nonisothermal thermal decomposition reaction kinetics of d-mannitol, J. Chem. Eng. Data, 55, 119-124, doi:10.1021/je900285w, 2010a.

Tong, B., Yu, Y., Tan, Z.-C., Meng, C.-G., Cui, L.-J., Xiao, G., and Liu, R.-B.: Thermodynamic investigation of several natural polyols (IV): heat capacities and thermodynamic properties of adonitol, Thermochim. Ac., 499, 117-122, doi:10.1016/j.tca.2009.11.011, 2010 b.

Verevkin, S. P.: Determination of vapor pressures and enthalpies of vaporization of 1,2-alkanediols, Fluid Phase Equilibr., 224, 23 29, 2004.

Verevkin, S. P.: Vapor pressures and enthalpies of vaporization of a series of the 1,3-alkanediols, J. Chem. Eng. Data, 52, 301-308, doi:10.1021/je060419q, 2007. 
Verevkin, S. P. and Schick, C.: Vapour pressures and heat capacity measurements on the C7-C9 secondary aliphatic alcohols, J. Chem. Thermodyn., 39, 758-766, 2007.

Verevkin, S. P., Krasnykh, E. L., Vasiltsova, T. V., Koutek, B., Doubsky, J., and Heintz, A.: Vapor pressures and enthalpies of vaporization of a series of the linear aliphatic aldehydes, Fluid Phase Equilib., 206, 331-339, 2003.

Verevkin, S. P., Emel'yanenko, V. N., and Nell, G.: 1,2-propanediol. Comprehensive experimental and theoretical study, J. Chem. Thermodyn., 41, 1125-1131, 2009.

Wang, Z., Wang, Q., Liu, X., Fang, W., Li, Y., and Xiao, H.: Measurement and correlation of solubility of xylitol in binary water+ethanol solvent mixtures between $278.00 \mathrm{~K}$ and $323.00 \mathrm{~K}$, Korean J. Chem. Eng., 30, 931-936, doi:10.1007/s11814-0120225-7, 2013.
Xie, M., Hannigan, M. P., and Barsanti, K. C.: Gas/particle partitioning of 2-methyltetrols and levoglucosan at an urban site in Denver, Environ. Sci. Technol., 48, 2835-2842, doi:10.1021/es405356n, 2014.

Zhang, Z. Y. and Yang, M. L.: Heat capacities and phase transitions of 1,1,1-trihydroxymethylpropane and pentaerythritol over the superambient temperature range, Thermochim. Ac., 156, 157$161,1989$.

Zuend, A., Marcolli, C., Booth, A. M., Lienhard, D. M., Soonsin, V., Krieger, U. K., Topping, D. O., McFiggans, G., Peter, T., and Seinfeld, J. H.: New and extended parameterization of the thermodynamic model AIOMFAC: calculation of activity coefficients for organic-inorganic mixtures containing carboxyl, hydroxyl, carbonyl, ether, ester, alkenyl, alkyl, and aromatic functional groups, Atmos. Chem. Phys., 11, 9155-9206, doi:10.5194/acp11-9155-2011, 2011. 